\section{A problem-based approach in musculoskeletal ultrasonography: central metatarsalgia}

\author{
Hye Min Son ${ }^{1}$, Jee Won Chai ${ }^{2,3}$, Yong Hee Kim ${ }^{2,3}$, Dong Hyun Kim ${ }^{2,3}$, Hyo Jin Kim ${ }^{2,3}$, \\ Jiwoon $\mathrm{Seo}^{2,3}$, Sung Moon Lee ${ }^{4}$
}

${ }^{1}$ Department of Radiology, Yeungnam University College of Medicine, Daegu; ${ }^{2}$ Department of Radiology, SMG-SNU Boramae Medical Center, Seoul; ${ }^{3}$ Department of Radiology, Seoul National University College of Medicine, Seoul; ${ }^{4}$ Daegyeong Imaging and Healthcare Center, Daegu, Korea

Ultrasonography (US) is a useful diagnostic method that can be easily applied to identify the cause of metatarsalgia. The superficial location of structures in the foot, dynamic capability of US, and the ability to perform direct real-time evaluations of the pain site are also strong advantages of US as a modality for examining the foot. Moreover, knowing the possible pain sources to investigate when a patient has a specific site of pain will enhance the diagnostic quality of US, and will help radiologists to perform US efficiently and effectively. The purpose of this article is to review the common etiologies of metatarsalgia including Morton's neuroma, plantar plate injury, synovitis, tenosynovitis, bursitis, and metatarsal fractures, and to discuss their US features.

Keywords: Metatarsalgia; Morton neuroma; Plantar plate; Forefoot; Ultrasonography

Key points: Ultrasonography is a useful diagnostic method that can be easily applied to identify the cause of metatarsalgia. Knowing the possible pain sources to investigate when a patient has a specific site of pain will enhance the diagnostic quality of ultrasonography. Morton's neuroma, intermetatarsal bursitis, plantar plate injury, metatarsophalangeal joint synovitis, metatarsal fracture, and submetatarsal bursitis should be considered in patients with central metatarsalgia.

\section{Introduction}

Metatarsalgia is a common problem in the general population that significantly reduces independence and quality of life, and it is also a known risk factor for locomotor disability, impaired balance, and increased risk of falls $[1,2]$. Various etiologies can present similar symptoms and similar physical examination findings, but they must be distinguished from each other because the treatment can be different [3-5]. As the clinical diagnosis based on the symptoms and physical examination can be misleading, ultrasonography (US) can be a problem-solving tool to make the correct diagnosis [6]. However, without knowing the differential diagnoses and the structures to evaluate, the radiologist might need to invest a considerable amount of time and effort to find the true pathology. Therefore, the purpose of this article is to review the possible etiologies of central metatarsalgia and their US

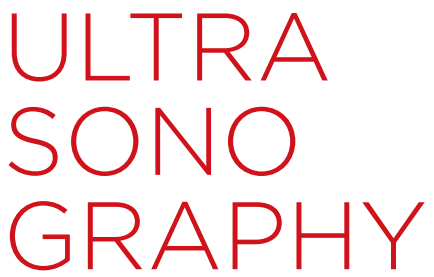

\section{REVIEW ARTICLE}

https://doi.org/10.14366/usg.21193 pISSN: 2288-5919 • elSSN: 2288-5943 Ultrasonography 2022;41:225-242

Received: Septmeber 10, 2021

Revised: September 10, 2021

Accepted: October 25, 2021

Correspondence to: Jee Won Chai, MD, Department of Radiology, SMG-SNU Boramae Medical Center, 20 Boramae-ro 5-gil, Dongjakgu, Seoul 07061, Korea

Tel. +82-2-870-2549

Fax. $+82-2-870-3531$

E-mail: chaijw@gmail.com

This is an Open Access article distributed under the terms of the Creative Commons Attribution NonCommercial License (http://creativecommons.org licenses/by-nc/4.0/) which permits unrestricted noncommercial use, distribution, and reproduction in any medium, provided the original work is properly cited.

Copyright (c) 2022 Korean Society of Ultrasound in Medicine (KSUM)

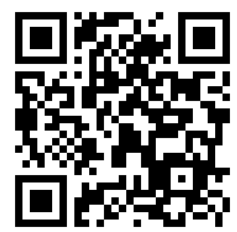

How to cite this article:

Son HM, Chai JW, Kim YH, Kim DH, Kim HJ Seo J, et al. A problem-based approach in musculoskeletal ultrasonography: central metatarsalgia. Ultrasonography. 2022 Apr;41(2):225-242. 
findings to aid radiologists in performing effective and efficient US examinations.

Common causes of metatarsalgia are Morton's neuroma, intermetatarsal bursitis, plantar plate injury, submetatarsal bursitis, synovitis of metatarsophalangeal (MTP) joint, and metatarsal fractures $[7,8]$. As there can be multiple pain sources, the forefoot should be evaluated with US according to each possible location of the disease. A suggested checklist is provided in the Table 1. Furthermore, careful history-taking and a basic radiographic evaluation should be done before US imaging to guide the examiners to focalize the US examination [8].

The US examination to evaluate the forefoot can be done with the patient in either the supine or sitting position according to the examiner's preference. When the patient's knee is flexed and feet flat on the bed, the dorsal side of the foot can be easily examined. When the patient's knee is extended and leg rests on the bed,

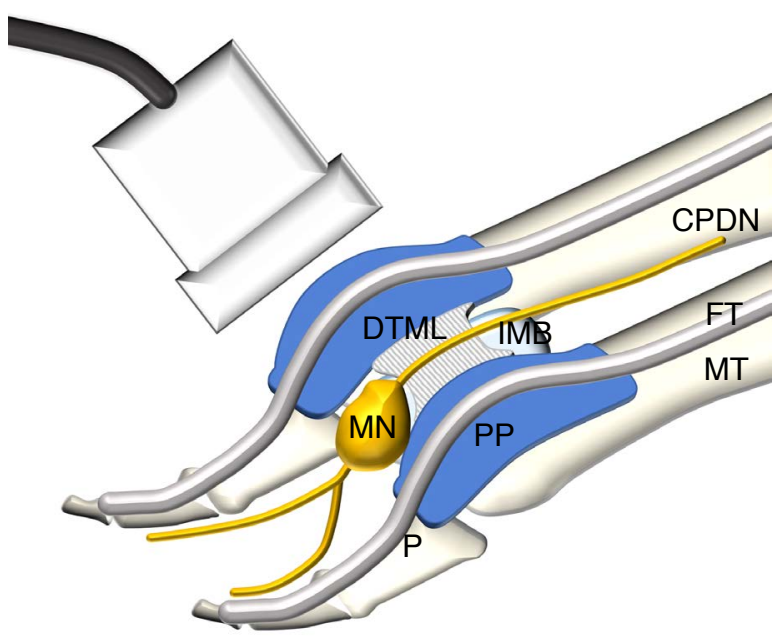

A

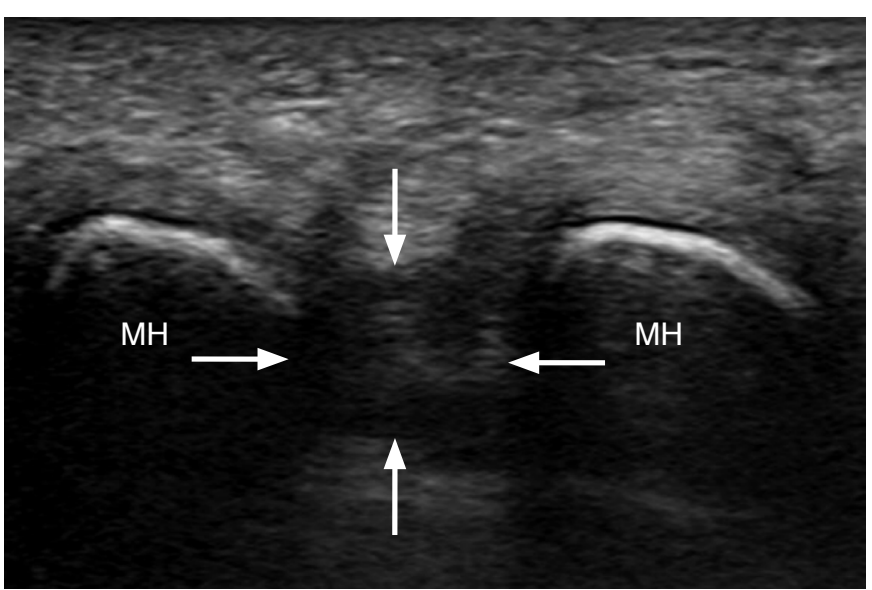

C

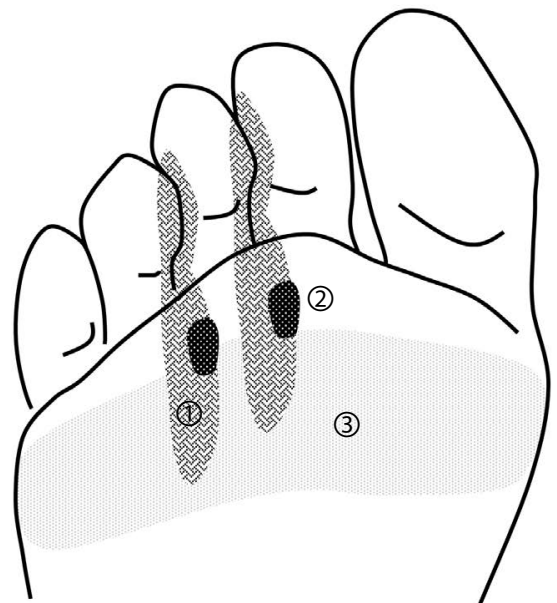

Fig. 1. The anatomic locations of pain corresponding to the common etiologies of metatarsalgia are illustrated on the plantar surface of the forefoot. 1, Morton's neuroma; 2, plantar plate injury; 3 , submetatarsal bursitis.

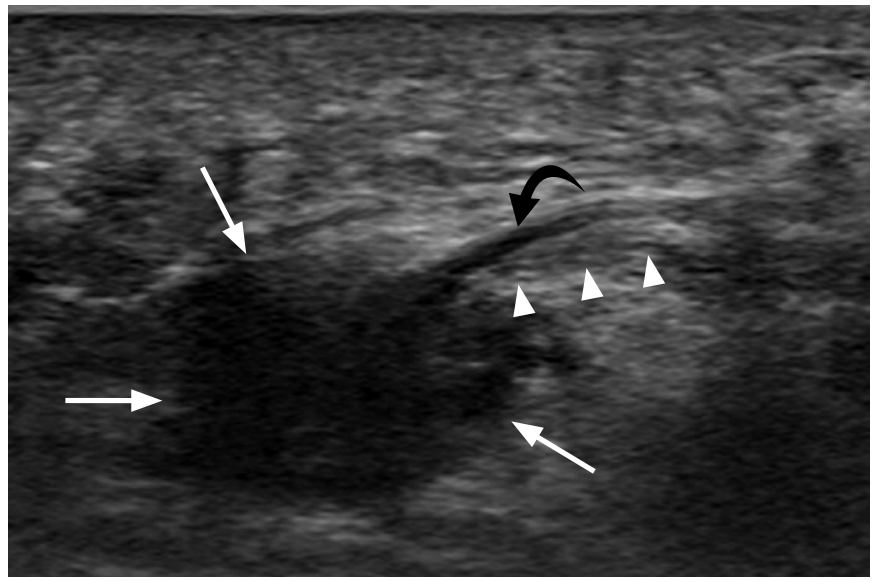

B

Fig. 2. A 78-year-old woman with Morton's neuroma at the second intermetatarsal space.

A. A schematic drawing of the intermetatarsal space anatomy is provided with the position of the transducer. CPDN, common plantar digital nerve; DTML, deep transverse intermetatarsal ligament; FT, flexor tendon; IMB, intermetatarsal bursa; MN, Morton's neuroma; MT, metatarsal bone; P, phalangeal bone; PP, plantar plate. B. Longaxis view of the intermetatarsal space, scanning from the plantar side, shows a low-echoic mass (white arrows) which is continuous with the common plantar digital nerve (black curved arrow). Deep transverse intermetatarsal ligament (white arrowheads) is visible as a flat structure beneath the course of the common plantar digital nerve. C. Short-axis view of the intermetatarsal space, scanning from the plantar side, shows a low-echoic mass (arrows) located at the level of the metatarsal head. MH, metatarsal head. 
both the plantar and dorsal surfaces of the foot can be evaluated without changing the position. This position also allows the most dynamic assessments and facilitates an easy comparison with the contralateral foot.

\section{Morton's Neuroma}

Morton's neuroma is a common problem of the foot that presents

Table 1. Common causes of metatarsalgia and the corresponding US checklist

\begin{tabular}{ll}
\hline \multicolumn{1}{c}{ Diagnosis } & \multicolumn{1}{c}{ US checklist } \\
\hline Morton's neuroma & Common plantar digital nerve \\
Intermetatarsal bursitis & Intermetatarsal bursa \\
Plantar plate injury & Plantar plate \\
Metatarsophalangeal joint synovitis & Metatarsophalangeal joint \\
Metatarsal fracture & Metatarsal bone \\
Submetatarsal bursitis & Submetatarsal fat-pad \\
\hline
\end{tabular}

US, ultrasonography.

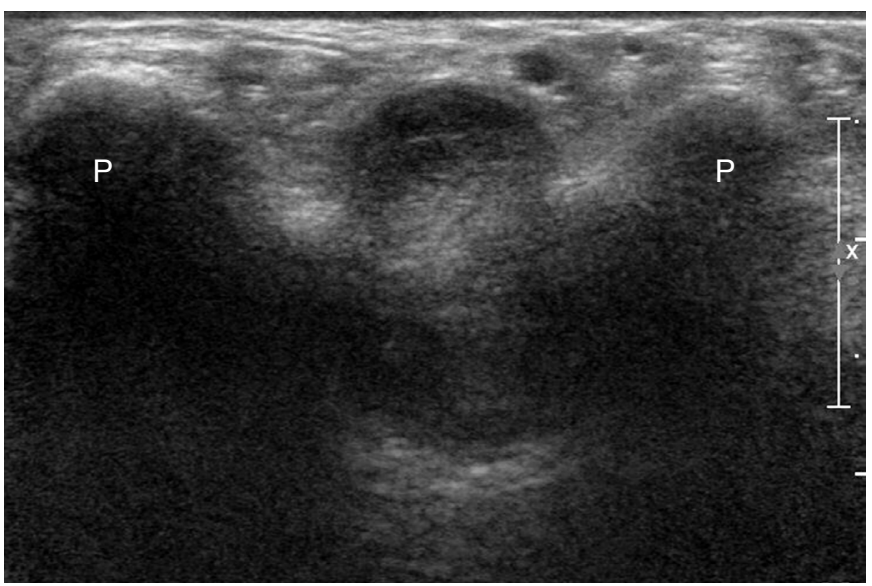

A

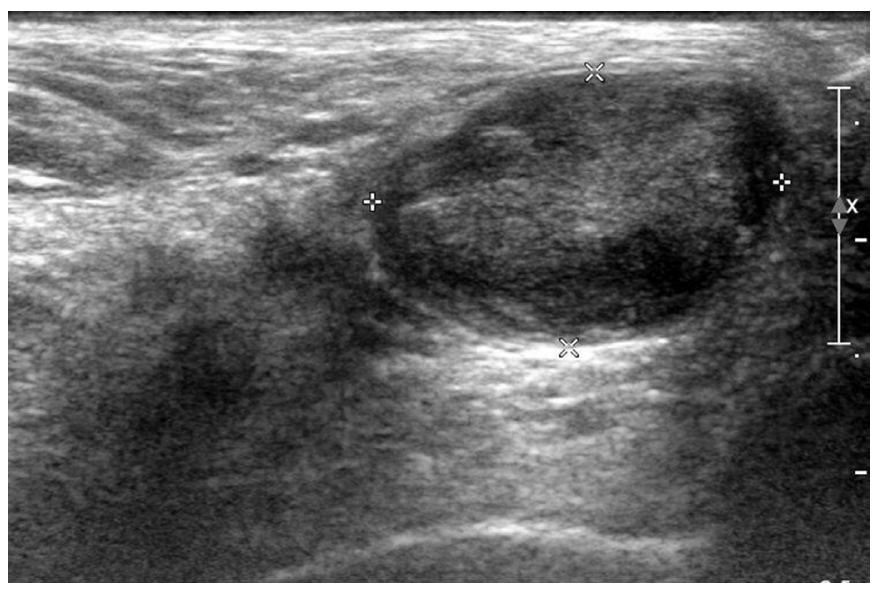

C metatarsalgia $[9,10]$. Histologically, it is a neuroma-bursal complex, which consists of an enlarged nerve with degeneration, perineural scarring, tangled vessels, and scarred intermetatarsal bursa around the nerve [11-13]. The main symptoms are burning pain in the plantar aspect of the forefoot and a feeling of fullness, or "walking on a pebble." Patients sometimes complain of tingling, numbness, or radiating pain in the affected toes $[3,9,10]$ (Fig. 1). Entrapment, ischemia, overuse, and repetitive trauma have been suggested as possible causes of Morton's neuroma, and variations in the anatomy of the forefoot may contribute to the development of symptoms $[9,10]$. Morton's neuroma most commonly affects the third web space, followed by the second web space [14-17], because the spaces are narrow in those regions [18].

US has been considered as an accurate modality to identify Morton's neuroma $[19,20]$. The patient can be examined with either a dorsal or plantar approach depending on the examiner's preference. First, in the dorsal approach, the intermetatarsal web space can be scanned with plantar flexion of the toes to visualize neuromas in the intermetatarsal space more superficially $[21,22]$.

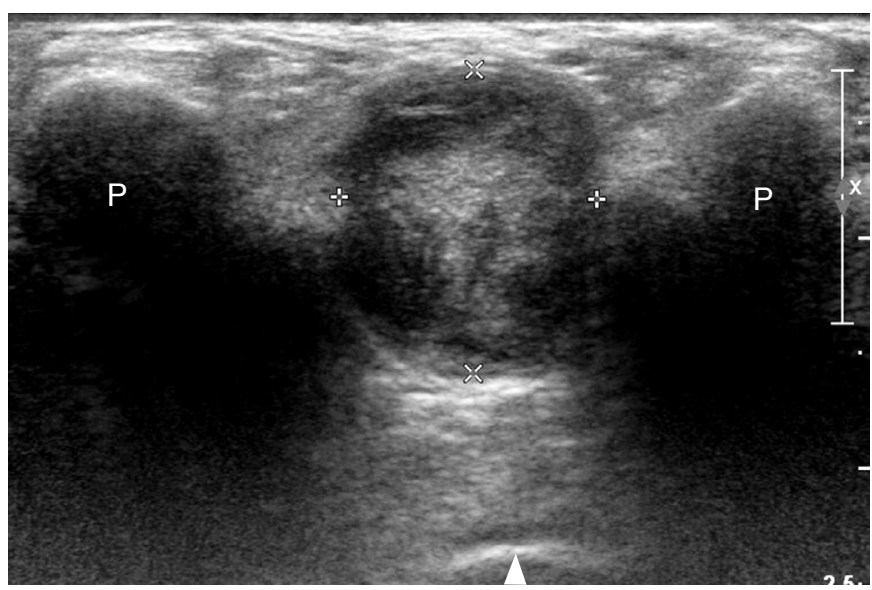

B

Fig. 3. A 46-year-old woman with a tenosynovial giant cell tumor, who presented with a palpable mass at the first web space.

A. On the short-axis view, scanning from the dorsal surface of intermetatarsal space, the mass is deeply located in the intermetatarsal space and the margin of the mass is poorly identified. P, proximal phalanx. B. On the short-axis view with compression at the plantar intermetatarsal space, the margin of the mass is more distinct and it is easier to appreciate the internal echo-texture of the mass. Note the compressed plantar surface (arrowhead) of the foot at the bottom of the figure. C. On the longaxis view with compression at the plantar intermetatarsal space, scanning from the dorsal side, the mass is a well-defined mass with an ovoid shape. There is no continuity between the common digital nerve and the mass. The mass was excised and the pathologic diagnosis was tenosynovial giant cell tumor, localized type. 
Second, in the plantar approach with dorsiflexion of the toes, the plantar surface of the foot can be scanned with pressure on the dorsal intermetatarsal spaces $[17,23]$. Compressing the opposite side of the intermetatarsal space helps to splay the metatarsal heads and increases the diagnostic accuracy for finding masses in this region $[17,22,23]$. The authors prefer the plantar approach because of the wider field of view from the intermetatarsal space to the MTP joint/plantar plate, which helps to differentiate Morton's neuroma from plantar plate injury.

On US, Morton's neuroma appears as a hypoechoic mass located in the intermetatarsal space at the level of metatarsal heads $[21,23]$ (Fig. 2). The long-axis view often allows the identification of continuity between the common plantar digital nerve and the neuroma. Detection of the plantar digital nerve entering the neuroma can raise the diagnostic accuracy for Morton's neuroma relative to other intermetatarsal masses such as complicated ganglion cysts or tendon sheath fibromas (Fig. 3).

Dynamic US originating from Mulder's clinical test can be done

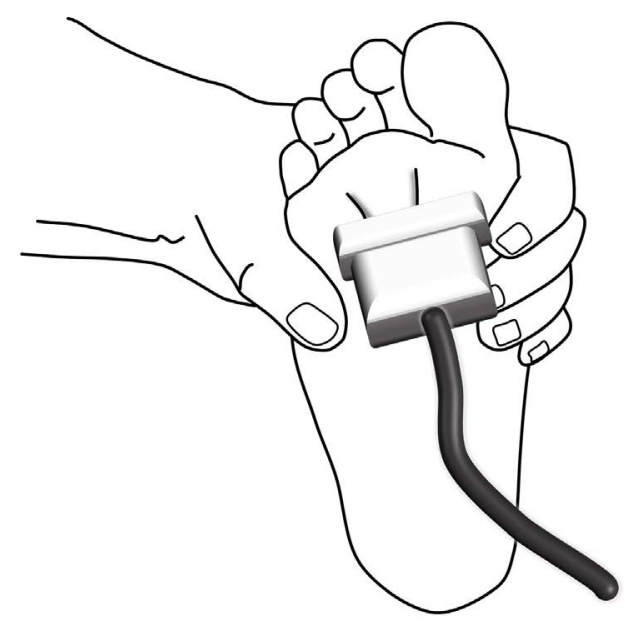

A

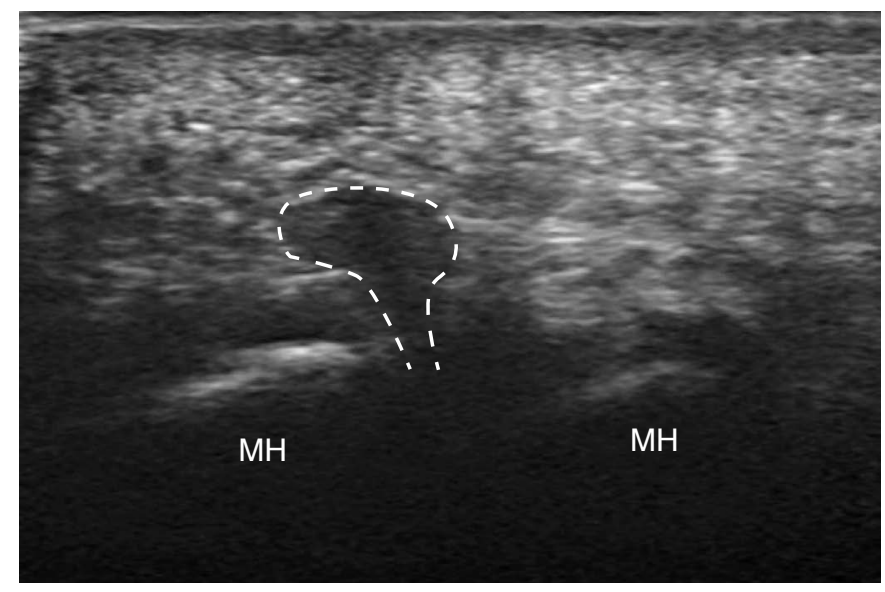

by the examiner squeezing or clasping the forefoot with his or her unused hand [24] (Fig. 4A). While applying some pressure at the plantar surface of intermetatarsal space on the short-axis view, the examiner can observe a hypoechoic mass, compressed between the metatarsal heads (Fig. 4B). When the examiner squeezes the forefoot further, with mild release of the pressure given by the transducer at the plantar surface, the mass is displaced superficially from the intermetatarsal space to the plantar aspect [24], resembling the shape of a gingko leaf [25] (Fig. 4C, Video clip 1). In patients with symptomatic neuroma, this maneuver may reproduce the characteristic shocking pain with a clicking sensation. This is called the "sonographic Mulder sign" [24].

The transverse dimension of the neuroma is more important to report than the longitudinal dimension because a lesion that is larger than $5 \mathrm{~mm}$ in the transverse dimension is usually considered symptomatic $[21,26]$. However, since several studies have found symptomatic neuromas smaller than $5 \mathrm{~mm}$ [27-29], it is important to search carefully and to apply a proper dynamic study with

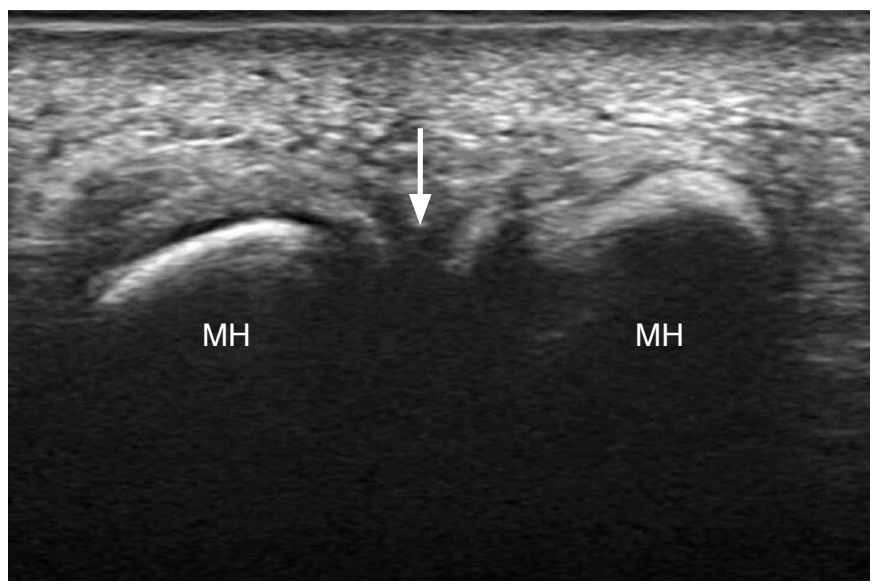

B

Fig. 4. A 61-year-old woman with Morton's neuroma.

A. The dynamic maneuver to perform sonographic Mulder test is illustrated. B. When mild pressure is placed on the plantar surface of the intermetatarsal space, the neuroma (arrow) is located deep between the two metatarsal heads (MHs). C. When the examiner squeezes the forefoot with the release of the pressure, the neuroma is displaced superficially to the plantar aspect with a stalk still connected to the intermetatarsal space, which resembles the shape of a gingko leaf (dashed line). 
correlation of typical symptoms in small lesions. Meanwhile, asymptomatic neuromas are also known to be commonly found in adults on imaging $[16,26]$. Therefore, the diagnosis of Morton's neuroma should be made with caution in asymptomatic patients.

\section{Intermetatarsal Bursitis}

Intermetatarsal bursitis is a potential cause of metatarsalgia that is often underdiagnosed or misdiagnosed [30]. It develops mostly due to blunt trauma, but sometimes it can be the first manifestation of inflammatory arthritis such as rheumatoid arthritis (RA) or gout $[30,31]$. Moreover, it is known that intermetatarsal bursitis contributes to the development of Morton's neuroma [32].

The intermetatarsal bursa is located in each intermetatarsal space at the dorsal side of the deep transverse intermetatarsal ligament (DTML) and common plantar digital nerve. Because the intermetatarsal bursa projects distally beyond the margin of the DTML at the second and third web space closely abutting the neurovascular bundle [32], intermetatarsal bursitis is often found simultaneously with and very close to Morton's neuroma (Fig. 5), making the neuroma seem oversized on imaging [13]. Dynamic examination with local pressure on the other side of the intermetatarsal space helps to differentiate bursitis from neuroma since the bursa changes in shape or collapses (Video clip 2), whereas the neuroma maintains its nodular shape and size [8].

On US, the intermetatarsal bursa is shown as a cystic lesion between the metatarsal heads and dorsal side of the DTML.
Intermetatarsal bursitis appears as hypoechoic thickening of the bursal wall with or without associated effusion. The bursal distension up to $3 \mathrm{~mm}$ in transverse dimension is not uncommon in asymptomatic populations and has been considered as a physiologic change [26]. However, in a recent large cohort study of RA patients with magnetic resonance imaging (MRI), most patients had intermetatarsal bursitis measuring $3 \mathrm{~mm}$ or smaller in the transverse dimension, and a size larger than $3 \mathrm{~mm}$ worked as a very specific cut-off value for RA (specificity, 98\%; sensitivity, 13\%) [33]. The authors additionally investigated the dorsoplantar dimension of intermetatarsal bursitis, but also there was a large overlap below $15 \mathrm{~mm}$ between RA and normal controls, such that a dorsoplantar dimension of $15 \mathrm{~mm}$ or larger served as a very specific cutoff for RA (specificity, 100\%; sensitivity, 16\%). Therefore, in patients with prominent intermetatarsal bursitis (Fig. 6), a thorough evaluation is needed to find other features of inflammatory arthritis.

\section{Plantar Plate Injuries}

The plantar plate is a rectangular trapezoid shape fibrocartilaginous structure that is firmly attached to the base of the proximal phalanx and resists hyperextension of the MTP joint [34-36]. The plantar plate and joint capsule may become attenuated and injured because of hyperextension forces to the MTP joint of smaller toes. A plantar plate injury can cause forefoot pain and some degree of deformity, resulting in dorsomedial subluxation or crossover toes in the advanced stage [35].

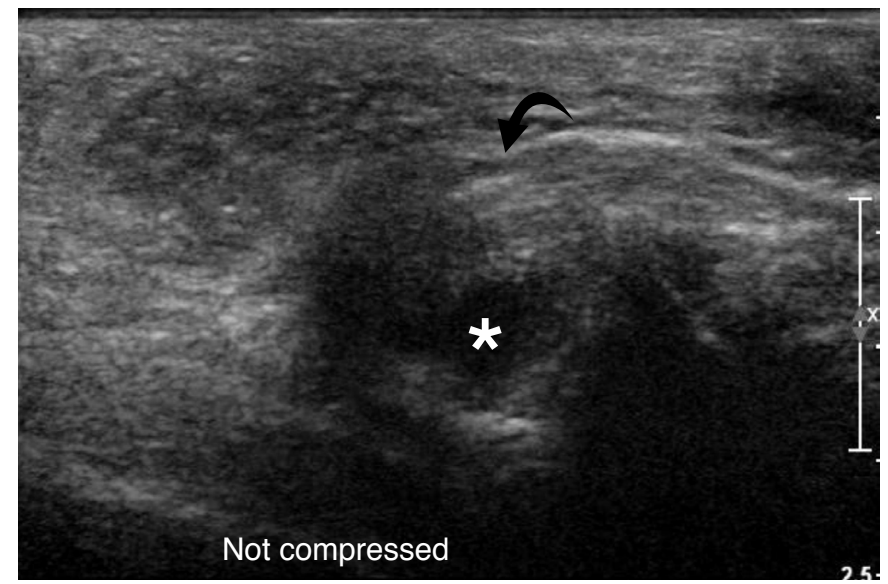

A

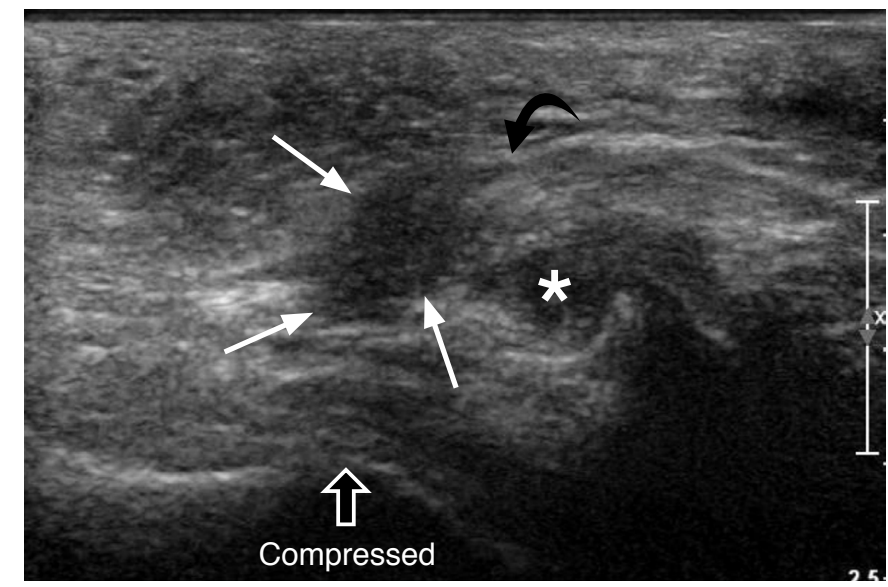

B

Fig. 5. A 20-year-old man with Morton's neuroma and intermetatarsal bursitis.

A. On the long-axis view of the intermetatarsal space, scanning from the plantar side, the Morton's neuroma-bursal complex is visible as a large low-echoic mass when not compressed. The intermetatarsal bursitis component (asterisk) shows slightly lower echogenicity than the neuroma component. Note that the lesion is continuous with the common plantar digital nerve (curved arrow). B. The curved arrow indicates the common plantar digital nerve. While applying local pressure at the dorsal surface of the intermetatarsal space (black arrow), the neuroma component (white arrows) and the bursitis component (asterisk) are distinguished from each other as two separate lesions. 


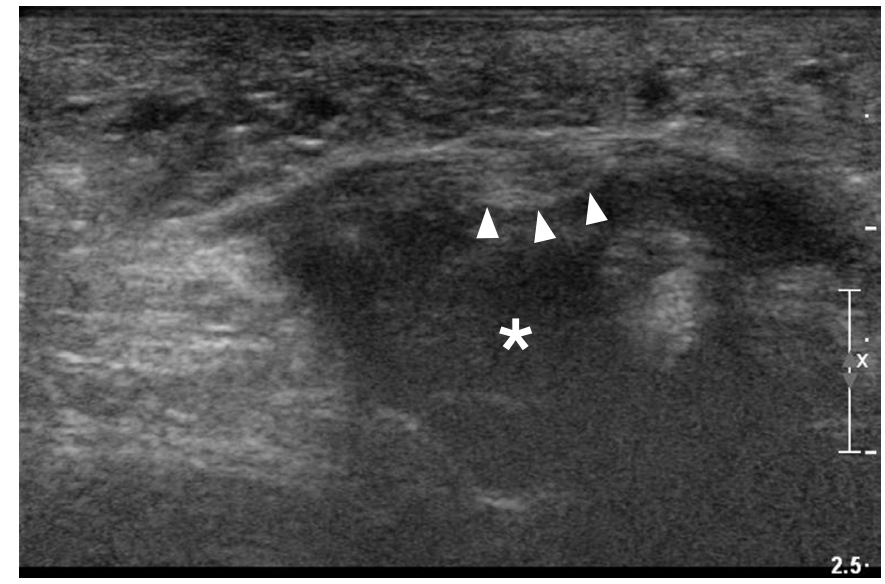

A

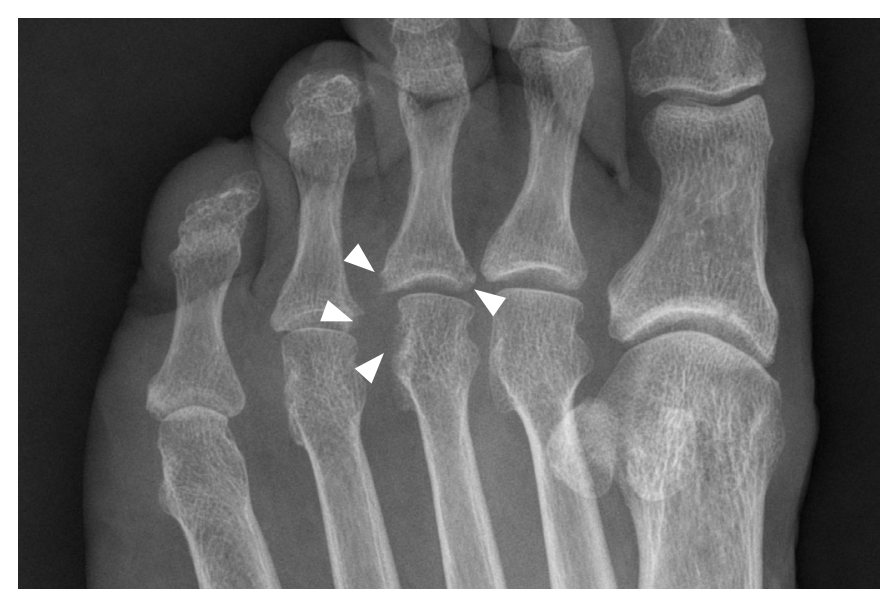

C

Because the most common site for injury is the lateral aspect of distal plantar plate insertion at the second MTP joint, the pain related to plantar plate injury is usually localized around the second toe proximal phalangeal base [36] (Fig. 1). When the lateral aspect of the second distal plantar plate insertion is injured, the affected toe deviates medially, and splaying of the second and third toes occurs. Further injury of the plantar plate results in hyperextension of the MTP joint with subsequent subluxation and dislocation. The MTP drawer test or vertical stress test (Hamilton-Thompson test) permits the provocative clinical assessment of MTP joint instability and grading [34] (Fig. 7), but a low-grade injury might demonstrate little or no instability upon stress [37]. A plantar plate injury can also produce symptoms similar to Morton's neuroma when there is reactive pericapsular soft tissue thickening (pericapsular fibrosis) pressing on the adjacent common plantar digital nerve or a concomitant Morton's neuroma [38]. Plantar plate injuries should be distinguished from Morton's neuroma, because a misdiagnosis would worsen the toe deformity and dysfunction.

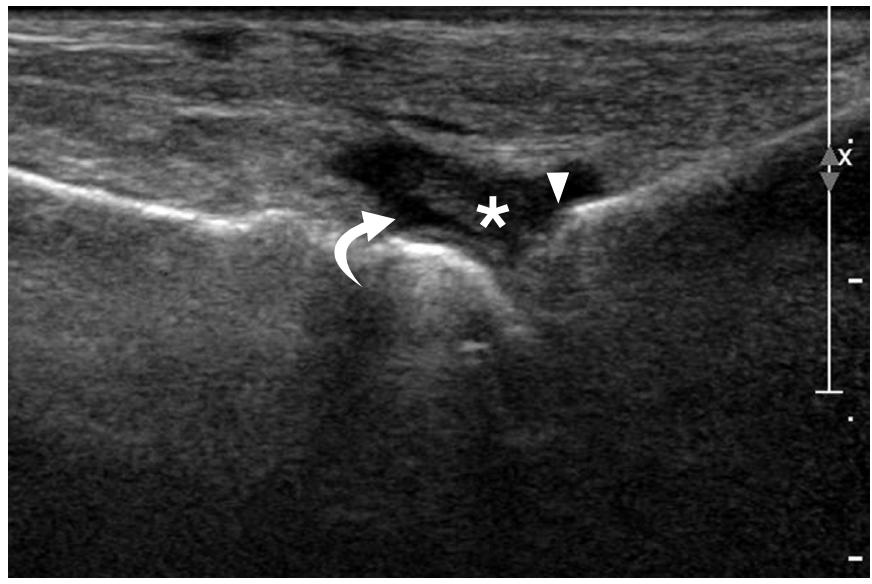

B

Fig. 6. A 65-year-old woman with metatarsalgia and the clinical impression of Morton's neuroma.

A. On the long-axis view of the third intermetatarsal space, scanning from the plantar side, the intermetatarsal bursa (asterisk) is extensively distended, with low-echoic synovial hypertrophy. Note that the bursa is located beneath and extends beyond the deep transverse intermetatarsal ligament (arrowheads). B. On the longaxis view of the third metatarsophalangeal joint scanning from dorsal side, dorsal recess of the joint is distended with synovial hypertrophy (asterisk) and small fluid (curved arrow). Note the loss of normal cortical margin at the base of proximal phalanx, which suggests a bone erosion (arrowhead). C. Oblique radiograph of the foot reveals erosions (arrowheads) at the third metatarsal head and third and fourth proximal phalangeal bases. The patient was further diagnosed with seropositive rheumatoid arthritis.

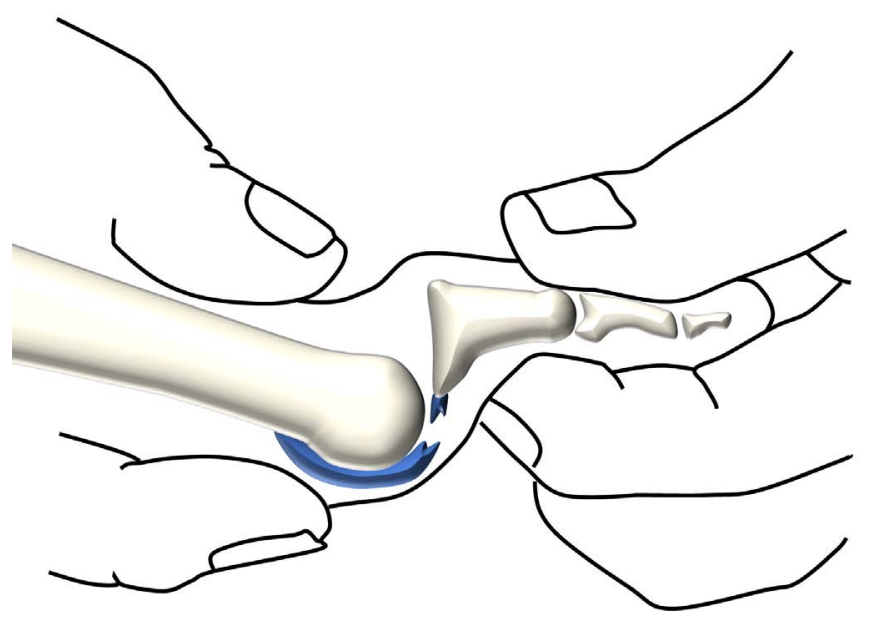

Fig. 7. A schematic drawing of the Hamilton-Thompson test. The test to evaluate the degree of metatarsophalangeal joint instability shows how dorsal subluxation occurs when the plantar plate is injured. 
Although MRI is accepted as the imaging modality of choice, US also shows a good correlation with the intraoperative finding of plantar plate injury [39-41]. On US long-axis view, the plantar plate normally appears as a homogeneously hyperechoic structure attached at the proximal phalangeal base [42]. It is important to tilt the transducer along with the distal insertion of the plantar plate to avoid the anisotropy artifact (Fig. 8) [43]. A hyperechoic triangular area can normally be seen in the central distal portion of the plantar plate [43]. A dynamic assessment with dorsiflexion of the toe can be performed to increase the sensitivity and accuracy of US for diagnosing plantar plate injuries $[40,44]$.

In plantar plate injuries, the plantar plate can show a focal full or partial thickness defect, diffuse thinning, or complete absence (Fig. 9) [42]. On a dynamic study, the true defect can be identified as an anechoic or hypoechoic tissue gap with dorsiflexion of the toe, sometimes interposed with fluid or herniated fat tissue (Video clips 3 , 4). Diffuse thinning of the plantar plate is considered significant when the distal plantar plate is thinner than its proximal or middle portion [42] (Video clip 5). When the plantar plate is completely torn and retracted, the flexor tendon can be found directly on the metatarsal head.

Known indirect signs of a plantar plate injury are the cartilage interface sign, flexor tendon/proximal phalangeal abnormalities, and pericapsular fibrosis. The flexor tendon can show subluxation into the torn gap of a plantar plate injury or medial subluxation from the central plantar plate groove [42]. Tenosynovitis can also

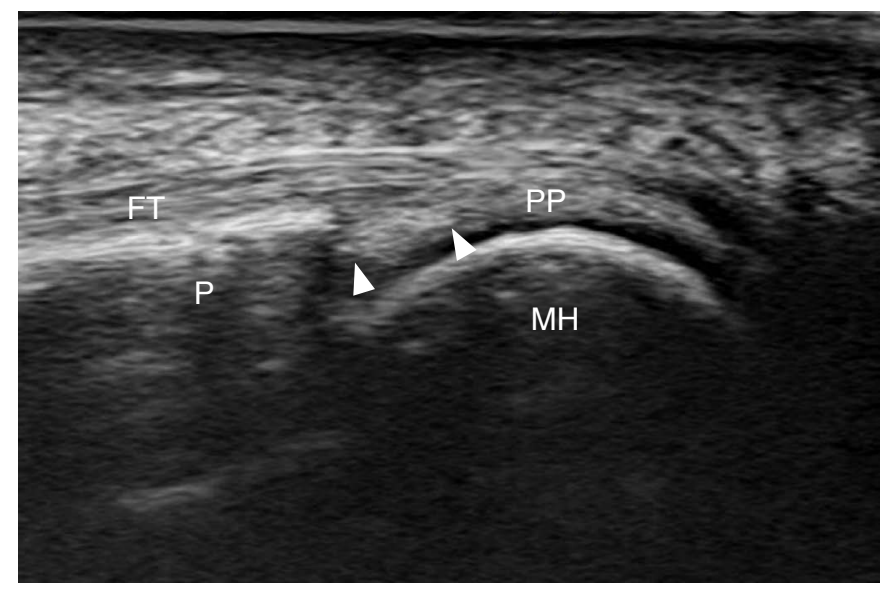

A

Fig. 8. A normal plantar plate (PP) of a 42-year-old woman.

A. On the long-axis view of PP scanning from the plantar surface of the foot, the normal PP is visible as a hyperechoic plate-like structure located between the flexor tendon (FT) and metatarsal head (MH) covered with anechoic articular cartilage. There is a triangular-shaped and more hyperechoic area (arrowheads) at the central distal plate, which is a normal finding. B. The same PP as A. When the angle of the ultrasound beam is not perpendicular to the distal PP, the middle to distal portion of the PP shows mild low echogenicity (white arrows) because of the anisotropy artifact. Arrowheads indicate the normal hyperechoic area at the central distal plate. P, proximal phalanx. 
[47]. When there is an increased amount of synovial-fluid complexes or synovial hypertrophy with intra-articular Doppler flow, active synovitis can be diagnosed on US [31].

\section{Rheumatoid Arthritis}

High-resolution US is a more sensitive method to detect early RA in regard to synovitis and erosions in the bone when compared to clinical examinations or radiographs $[48,49]$. Every single small joint of the foot is well accessible by US, especially the first and fifth MTP joints and interphalangeal joints. Pressing a small-footprint hockeystick transducer into the interdigital space may help to evaluate regions with limited exposure for US examination, such as the radial and ulnar sides of the second, third, and fourth MTP joints [47]. Common findings in RA are synovitis, joint effusion, bone erosions, and tenosynovitis [47].

Synovitis can be diagnosed if there is abnormally hypertrophied synovial tissue that may exhibit Doppler signals, regardless of effusion [50] (Fig. 11). Bone erosion is an intraarticular discontinuity

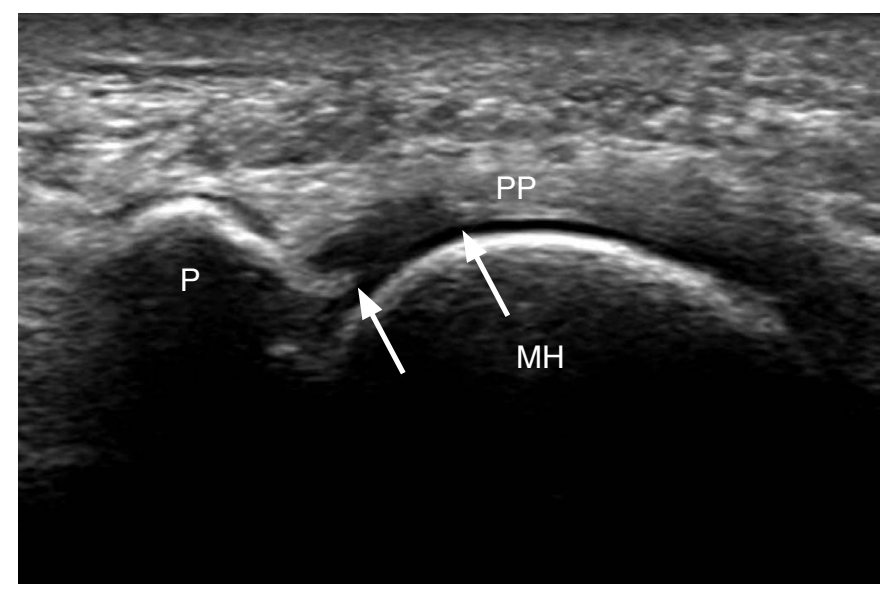

A

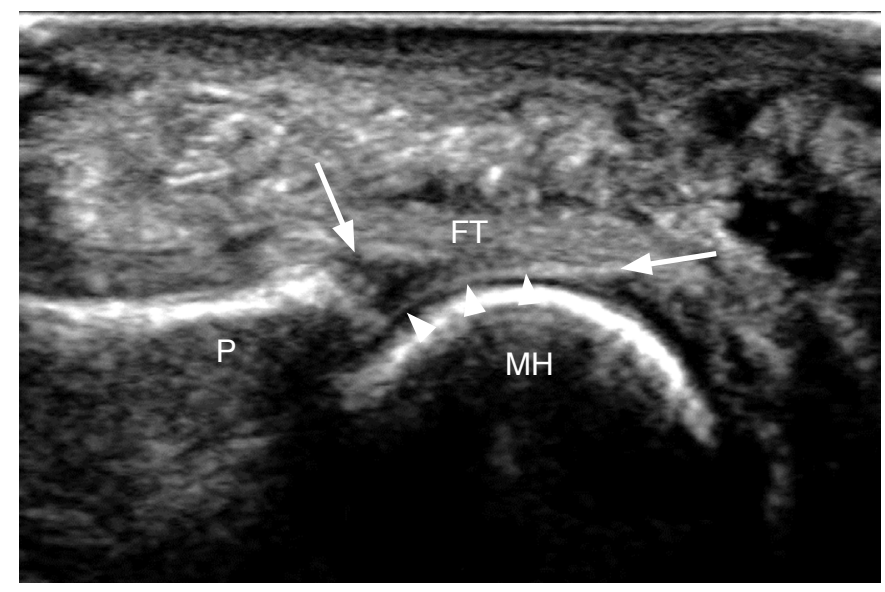

C of bone surface, visible in two perpendicular planes [51]. A normal smooth, shallow depression at the dorsal edge of the metatarsal head should not be mistaken for erosion [47]. Because synovial inflammation and proliferation is the primary pathologic process, resulting in marginal erosions at "bare areas," no bone damage occurs in the absence of synovitis [52]. Therefore, a focal depression of bone that does not have synovitis adjacent to it is unlikely to be true erosion. Tenosynovitis can be diagnosed when there is abnormal anechoic/hypoechoic tendon sheath widening with abnormal tenosynovial fluid or synovial hypertrophy [51]. Plantar tenosynovitis is more frequently found in patients with early inflammatory arthritis, even without MTP joint synovitis, than in the healthy population [53].

Synovitis, small joint effusion, or tenosynovitis can also be seen in non-inflammatory arthropathies such as overuse or degenerative arthritis, and it is difficult to differentiate these conditions from those caused by early inflammatory arthritis. However, inflammatory arthritis has a typical location (e.g., the fifth MTP joint in RA) where it develops in its early stages, and it often involves the bilateral

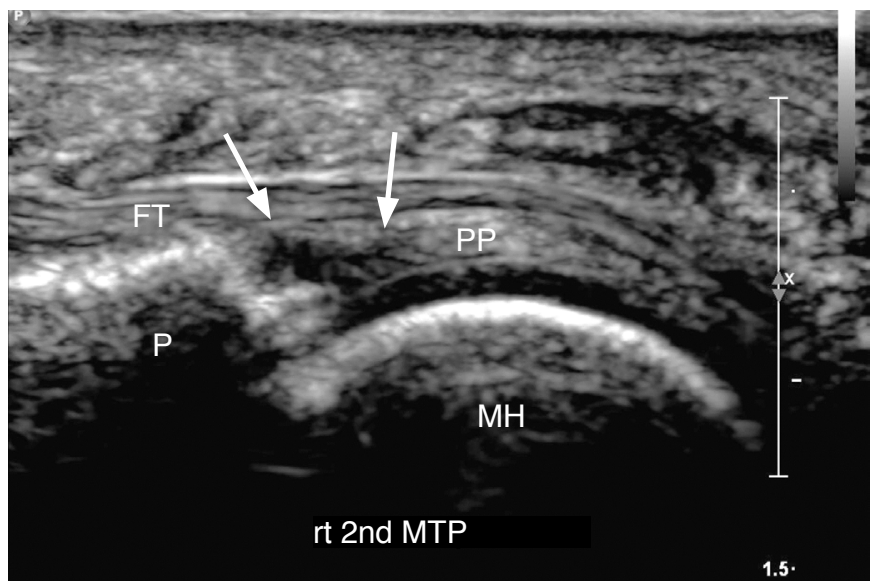

B

Fig. 9. Plantar plate (PP) injuries of variable degrees.

A. Partial-thickness PP injury in a 59-year-old woman is shown. The long-axis view of the PP shows a partial-thickness defect (arrows) at the lateral distal PP of the second metatarsophalangeal (MTP) joint. B. Full-thickness PP injury in a 75-year-old woman is shown. The long-axis view of the PP shows a full-thickness defect (arrows) at the distal PP of the second MTP joint. C. A complete tear of the PP in a 75-year-old woman is shown. A long-axis view of the plantar side of MTP joint shows a complete absence (arrows) of the PP beneath the flexor tendon (FT) and the tendon directly abuts the metatarsal head $(\mathrm{MH})$. Note the "cartilage interface sign," which is a well-visualized hyperechoic surface of the MH cartilage (arrowheads) because of the absence of PP. P, proximal phalanx. 
extremities. Furthermore, typical bone erosion or joint deformities can be clues in the chronic stage [54]. Another strength of US is the flexible field of view or site of examination. Other typical locations of inflammatory arthritis elsewhere in the body (e.g., the wrist joints in RA, knee joints in gout) are also readily accessible with US to

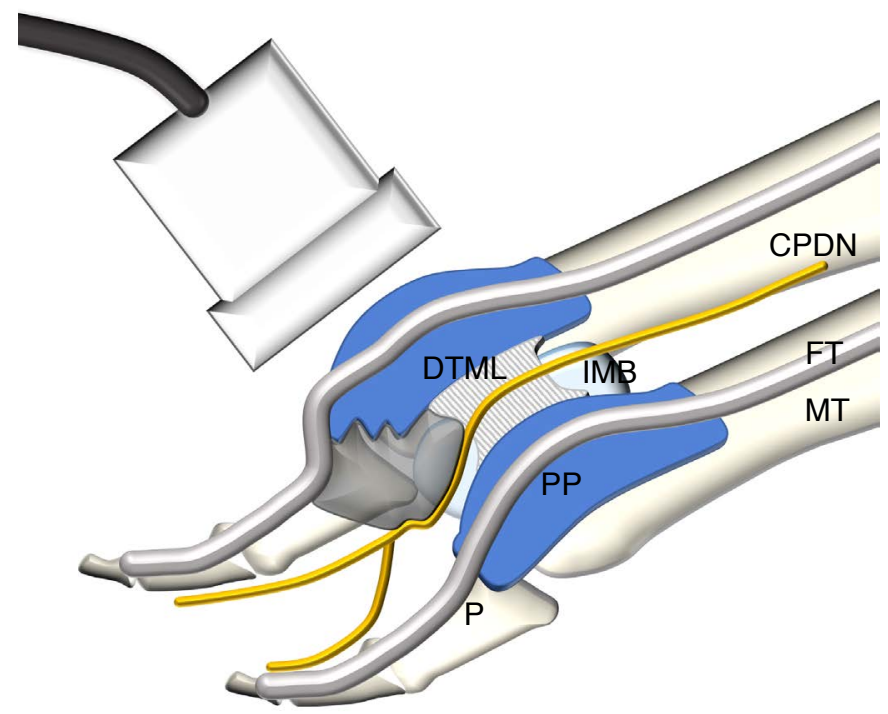

A

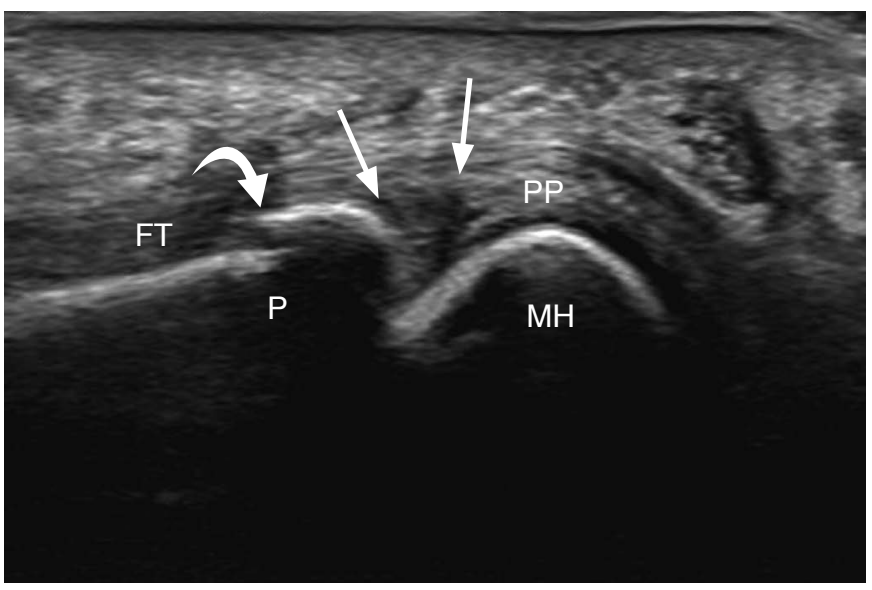

C

Fig. 10. A 72-year-old woman with a plantar plate (PP) injury.

A. A schematic drawing of pericapsular fibrosis is provided with the anatomy of the intermetatarsal space. CPDN, common plantar digital nerve; DTML, deep transverse intermetatarsal ligament; FT, flexor tendon; IMB, intermetatarsal bursa; MT, metatarsal bone; P, proximal phalanx. B. A standing anteroposterior radiograph shows splaying of second and third toes (lines), which is one of the radiographic features of PP injury. Other visible deformities are hallux valgus, lateralization of third metatarsophalangeal angle and subluxation of the fourth metatarsophalangeal joint. Subluxation of the fourth metatarsophalangeal joint (arrow) can be appreciated and was also associated with the PP injury, which is not shown in the figure. C. Ultrasonography long-axis view of the PP, scanning from the plantar side shows the nearly full-thickness defect (arrows) at the central distal PP. Note the osteophyte (curved arrow) at the proximal phalangeal base, caused by the secondary osteoarthritic change of the metatarsophalangeal joint. $\mathrm{MH}$, metatarsal head. D. Ultrasonography short-axis view of the PP, scanning from the plantar side, shows a low-echoic mass-like lesion in the intermetatarsal web space (arrow), which resembles the appearance of Morton's neuroma. However, the low-echoic mass-like lesion is more elongated and has a wide base at the second metatarsophalangeal joint, raising the possibility of pericapsular fibrosis. 
modality for crystal-induced arthropathies, including gout and calcium pyrophosphate dihydrate (CPPD) crystal deposition disease. Particularly in gouty arthritis, US plays a valuable role in the early diagnosis and monitoring treatment response [55]. In gouty arthritis, deposited monosodium urate (MSU) crystal on the surface of the hyaline cartilage shows another hyperechoic line added to the hyperechoic line formed by the subchondral bone, which is named the "double-contour sign" [56] (Fig. 12A). This sign should not be confused with the normal thin hyperechoic line at the surface of the cartilage in the area where the US beam is perpendicular to the cartilage surface [57]. MSU deposition at the cartilage surface is usually stippled, irregular in thickness, as bright as the subchondral

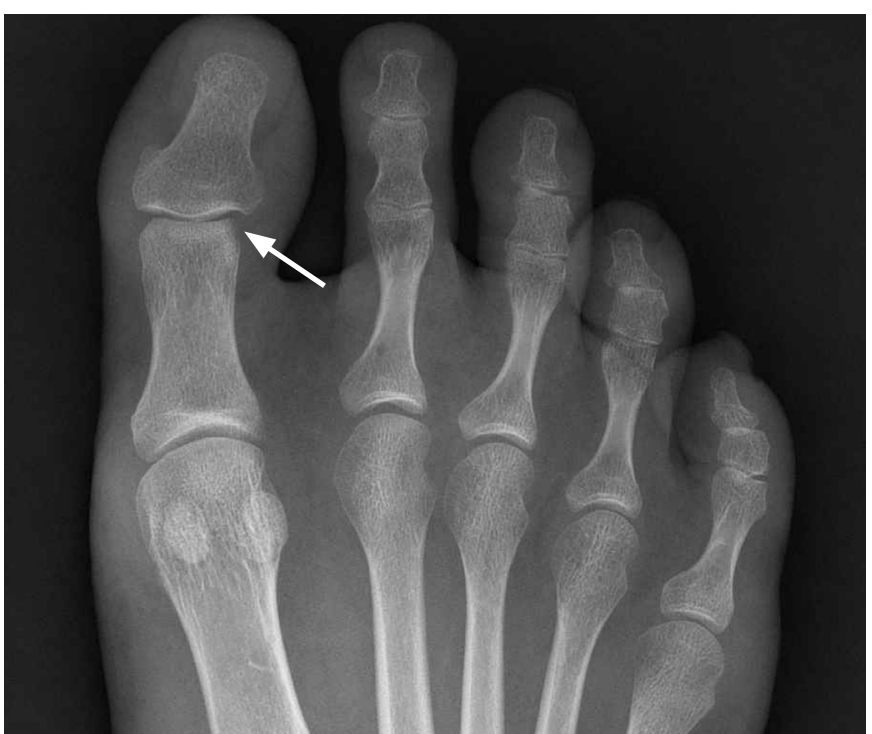

A

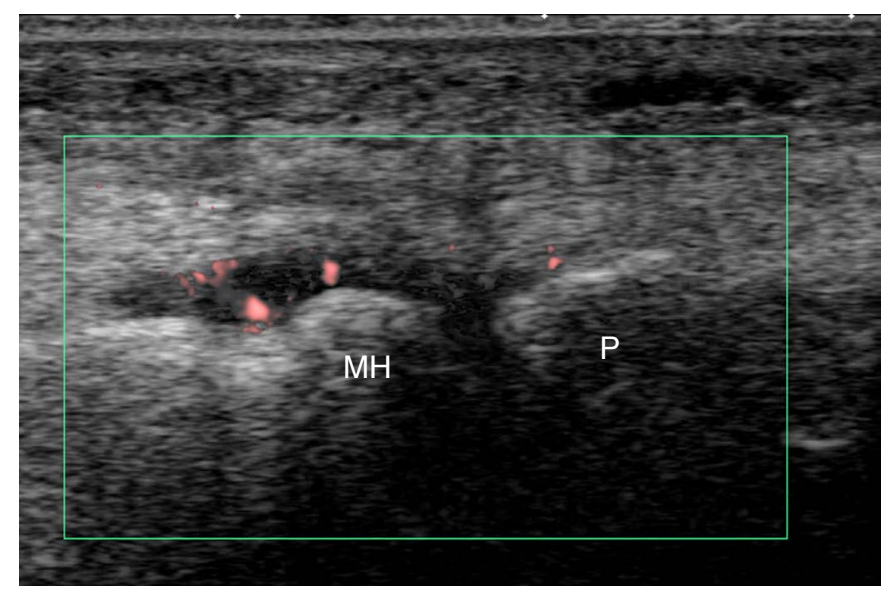

C

Fig. 11. A 33-year-old woman who presented with metatarsalgia.

A. Standing anteroposterior radiograph of the right foot shows periarticular osteopenia at multiple metatarsophalangeal (MTP) joints and interphalangeal joints with marginal erosion (arrow) at first proximal phalangeal head fibular side. B.On the long-axis view of the third MTP joint, scanning from the dorsal side shows a small effusion (curved arrow) and synovial hypertrophy (asterisks) in the distended dorsal recess. Note the normally smooth and corticated depression (arrowhead) at the dorsal edge of the metatarsal head (MH), which should not be confused with bone erosion. C. Doppler ultrasonography shows increased vascularity in the hypertrophied synovium. D. On the long-axis view of the intermetatarsal space scanning from the plantar side shows distension and synovial hypertrophy in the intermetatarsal bursa (asterisk) at the dorsal side of the deep transverse intermetatarsal ligament (arrowheads). Note the minimal change of the overlying plantar digital nerve (curved arrow) in contrast to the prominent distension of the intermetatarsal bursa (asterisk). This patient was further diagnosed with early seropositive rheumatoid arthritis. P, proximal phalanx. 
bone, and visible on any angle independent of reflectivity of US [58]. The reported sensitivity of the double-contour sign for diagnosing gout ranges from $25 \%$ to $95 \%[59,60]$. Effusion in gouty arthritis can be variably anechoic to heterogeneously hyperechoic (Fig. 12B). In some cases, hyperechoic aggregates float in the synovial recess with a gentle compression resulting in a "snow-storm appearance" [57]. Gout tophi can show various morphologies, from heterogeneous hypoechoic to hyperechoic nodular or amorphous lesions accumulated in the intra-/extra-articular bone or soft tissues (Fig. 12C), sometimes outlined by a hypoechoic halo that might correspond to the surrounding loose fibrovascular zone of tophi [61]. The bone erosions associated with gout may be closer to the diaphysis, deeper, and more irregular in shape with overhanging edges when compared to those in RA $[47,62]$.

CPPD arthropathy is caused by the deposition of CPPD crystals in

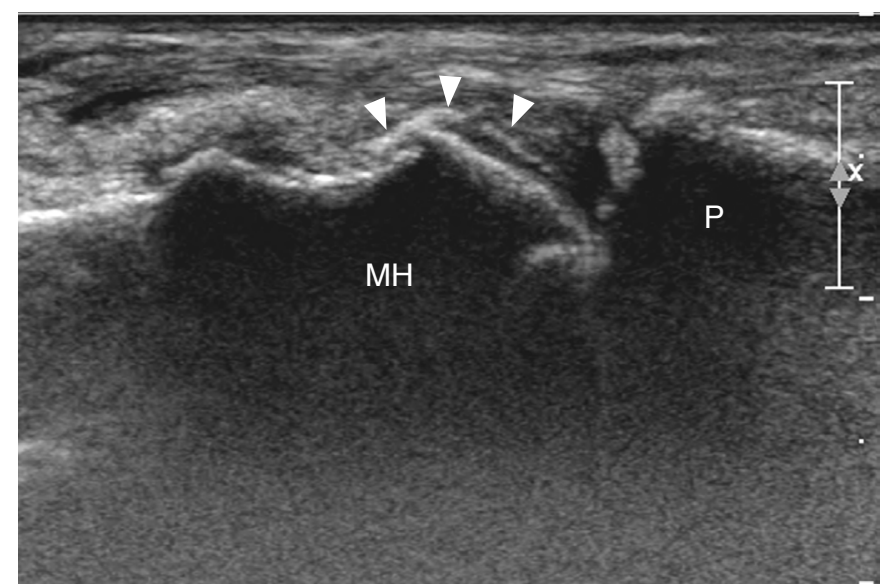

A

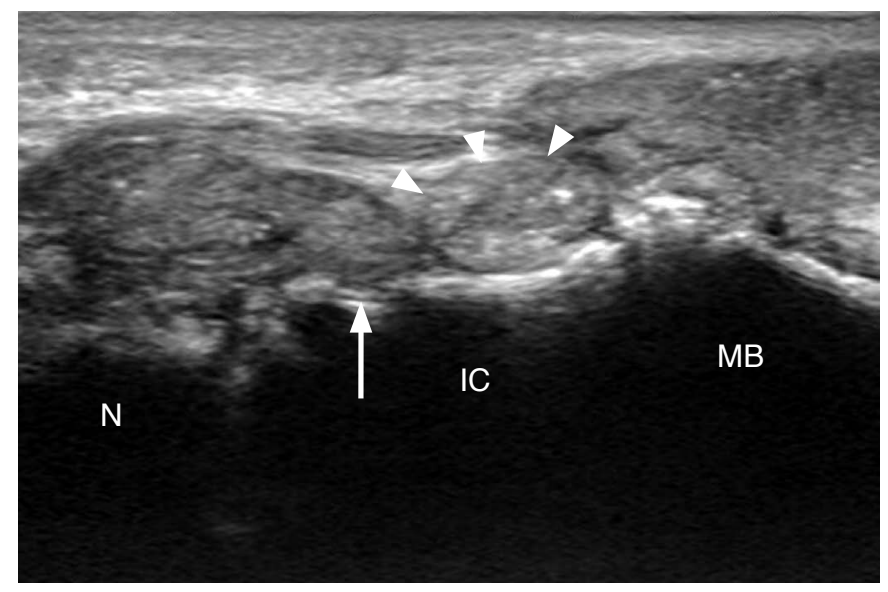

C the articular and periarticular tissues. CPPD arthropathy commonly involves the knee, wrist, symphysis pubis, and hip, leaving the foot as a rare site [63]. Similar to gouty arthritis, CPPD arthropathy can demonstrate synovitis with echogenic aggregates or floating echogenic foci in the synovial fluid. Linear calcifications in the tendon or ligaments also can be found in CPPD arthropathy. However, unlike gout, CPPD crystals tend to accumulate in the middle layer of the cartilage, parallel to the bony cortex. They appear as an echogenic line or dotted foci inside the hypoechoic hyaline cartilage with a preserved hyaline cartilage surface. In addition, CPPD crystals are frequently found in fibrocartilaginous tissues, such as the menisci of the knee and the triangular fibrocartilage of the wrist. These characteristic features and screening of frequently involved sites with radiographs or US allow a differential diagnosis between gout and CPPD arthropathy in the majority of cases [57]

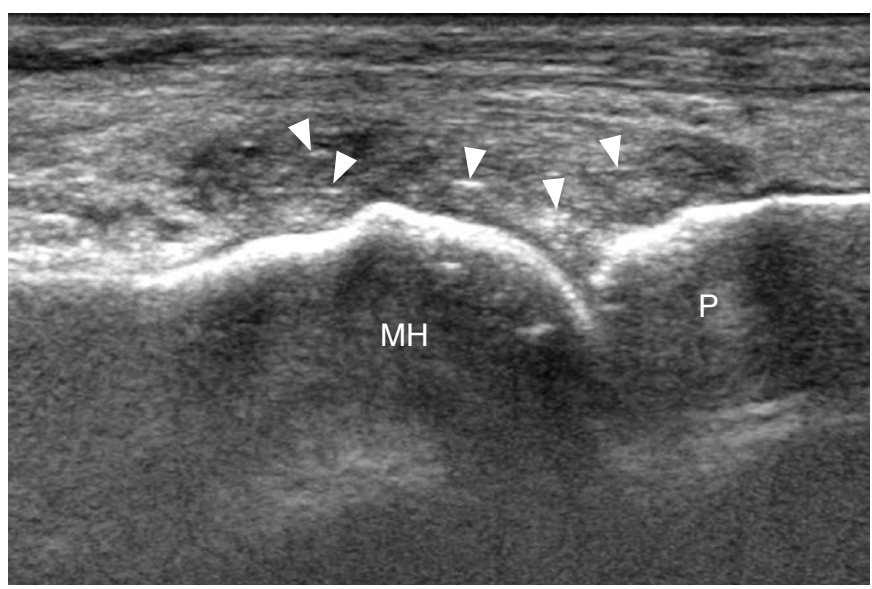

B

Fig. 12. Multiple ultrasonography features of gouty arthritis.

A. A 70-year-old man with gouty arthritis presented. A long-axis view of the first metatarsophalangeal (MTP) joint scanning from dorsolateral side shows an irregular hyperechoic line (arrowheads) on the surface of hyaline cartilage in addition to the normal hyperechoic contour of the metatarsal head $(\mathrm{MH})$, which is called the "double contour sign." B. A 44-year-old man with gouty arthritis presented. On the long-axis view of the first MTP joint, scanning from the dorsal side, the dorsal recess is distended with heterogenous hypoechoic synovial hypertrophy and floating hyperechoic monosodium urate crystal aggregates (arrowheads). C. A 37-year-old woman with gouty arthritis presented. A long-axis view of the midfoot scanning from the dorsal side shows multiple heterogenous extra-articular nodular tophi with surrounding hypoechoic halos (arrowheads). Note the more distant location of the bone erosion (arrow) from the joint margin, which is one of the features distinguishing gouty arthritis from rheumatoid arthritis. IC, intermediate cuneiform; MB, metatarsal base; N, navicular; P, proximal phalanx. 
(Fig. 13).

\section{Metatarsal Fractures}

Fractures of the lesser metatarsals usually occur at the mid to distal shaft or subchondral region of the metatarsal heads [64]. Metatarsal shaft fractures frequently involve the second and third metatarsals, whereas subchondral fractures mostly involve the second metatarsal head, followed by the third and fourth metatarsal heads [65]. Subchondral fractures related to osteochondrosis of the metatarsal heads (Freiberg's infraction) in adolescents are commonly discussed in this category, because their imaging findings are known to be similar to those of subchondral fractures in adults.

Radiographs are often unremarkable at the onset of symptoms

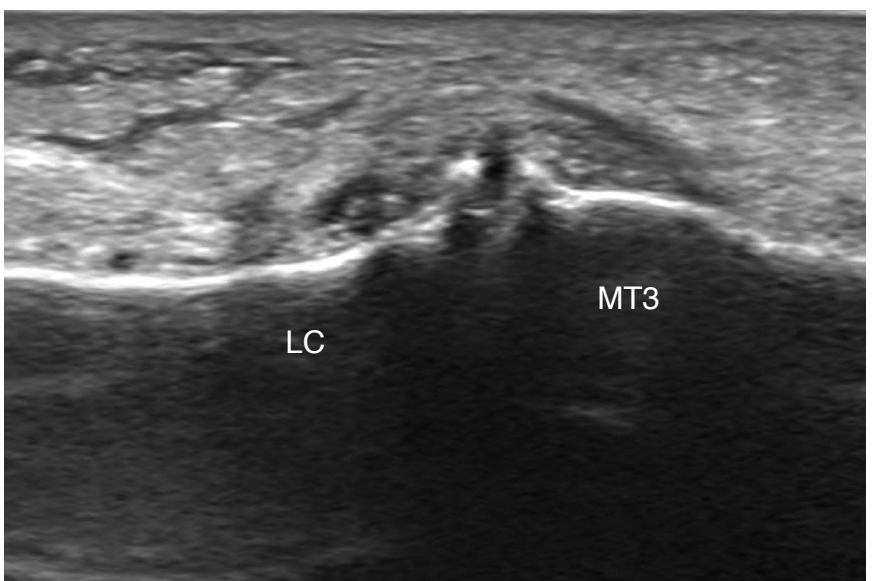

A

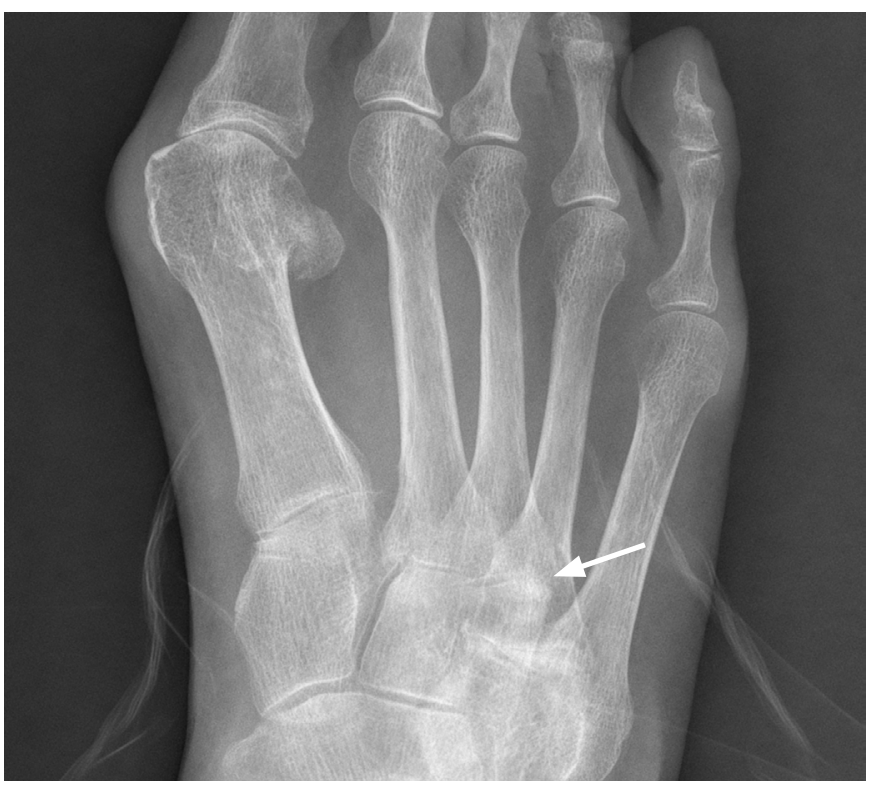

C

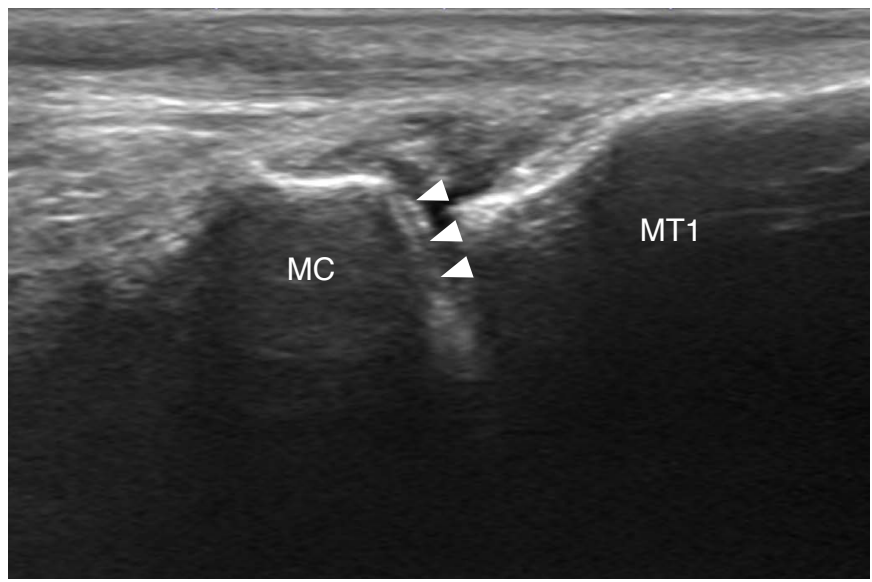

B

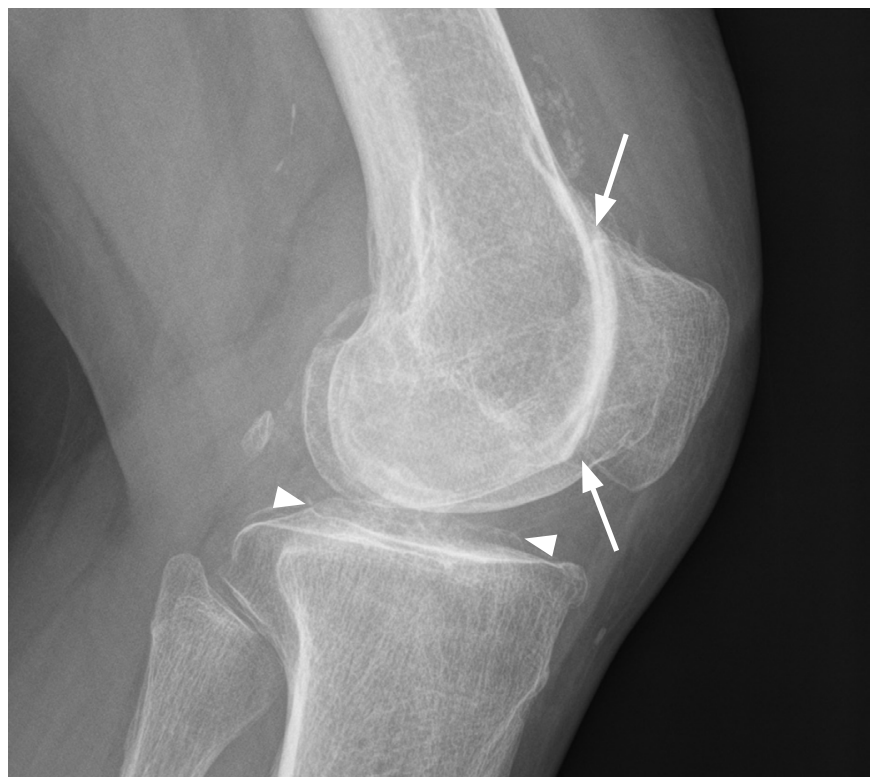

D

Fig. 13. An 80-year-old woman with calcium pyrophosphate dihydrate arthropathy who had a painful mass at the midfoot area.

A. Long-axis view of the third tarsometatarsal (TMT) joint scanning from the dorsal side shows osteophytosis and capsular thickening with tiny echogenic calcifications. B. Long-axis view of the first TMT joint scanning from the dorsal side shows another echogenic line (arrowheads) over the normal hyperechoic line formed by the subchondral bone plate. Furthermore, the interosseous ligament and joint capsule are thickened with some echogenic foci. C. Standing anteroposterior radiograph of the foot shows prominent degenerative changes without erosion at the TMT joints (arrow) and some metatarsophalangeal joints. D. Lateral radiograph of the knee shows chondrocalcinosis in the menisci (arrowheads) and prominent arthritic change at the patellofemoral joint (arrows). LC, lateral cuneiform; MC, medial cuneiform; MT, metatarsal bone. 
because metatarsal fractures may be subtle or occult (Fig. 14A), and cortical stress reaction or callus formation can obscure the lucent fracture lines. In such cases, MRI or bone scintigraphy has been used to find clinically suspected, but radiographically occult fracture lines. Although MRI permits the best visualization of stress-related bone marrow edema and parosteal soft tissue changes even in the early stage, high-resolution US has become an emerging initial diagnostic method since it is commonly available in sports clinic offices and is easily accompanied by a physical examination on-site [66].

Metatarsal shaft fractures are frequently found on the dorsal side of the foot because of the superficial location and because the cortical bone is best evaluated when the US beam is perpendicular to the cortex. The dorsal side of the metatarsal head, where subchondral fractures usually occur, can be evaluated with or without plantar flexion of the toes. However, US has some limitations in evaluating the central and plantar sides of the metatarsal head. Therefore, radiographs and US should be used complementarily to each other.

Normal cortical bone appears as a smooth echogenic line with a reverberation artifact and posterior acoustic shadowing on US [66]. The earliest US findings of a stress reaction or fracture of metatarsal shaft are hypoechoic periosteal elevation and hypervascularity. When the stress reaction progresses into an overt fracture, the following US findings can be seen: interruption of the smooth cortical line (step off, gap, or displacement of the cortex), cortical irregularity or thickening by callus formation, and hyperechogenicity of the surrounding soft tissue because of edema [66] (Fig. 14B, C). Joint effusion is usually present with cortical abnormalities in recent metatarsal head and neck fractures, whereas degenerative changes of the joint can be seen in a remote fracture [64] (Fig. 15).

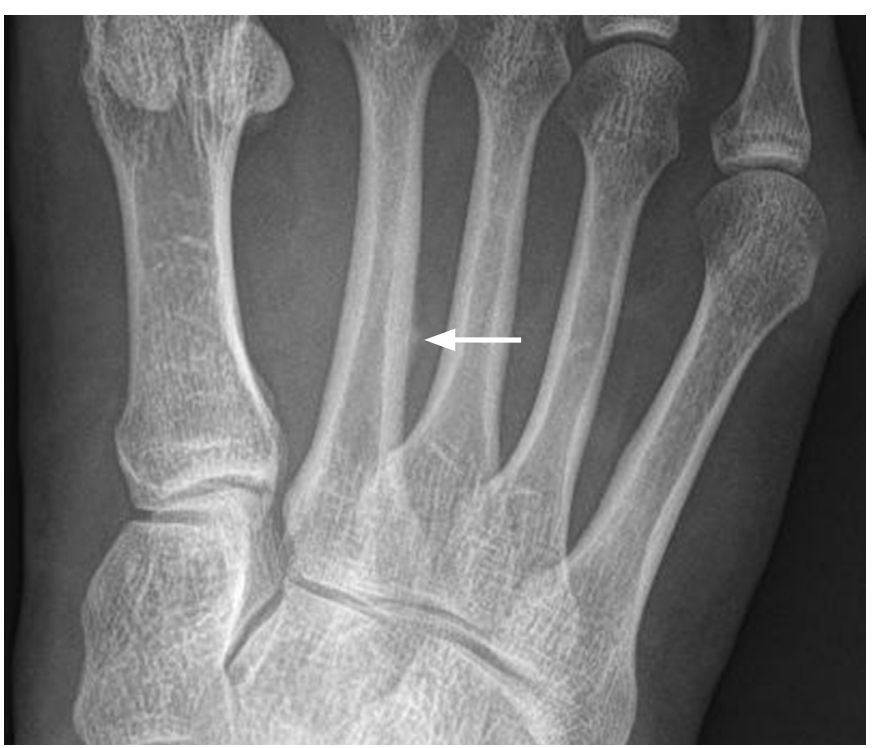

A

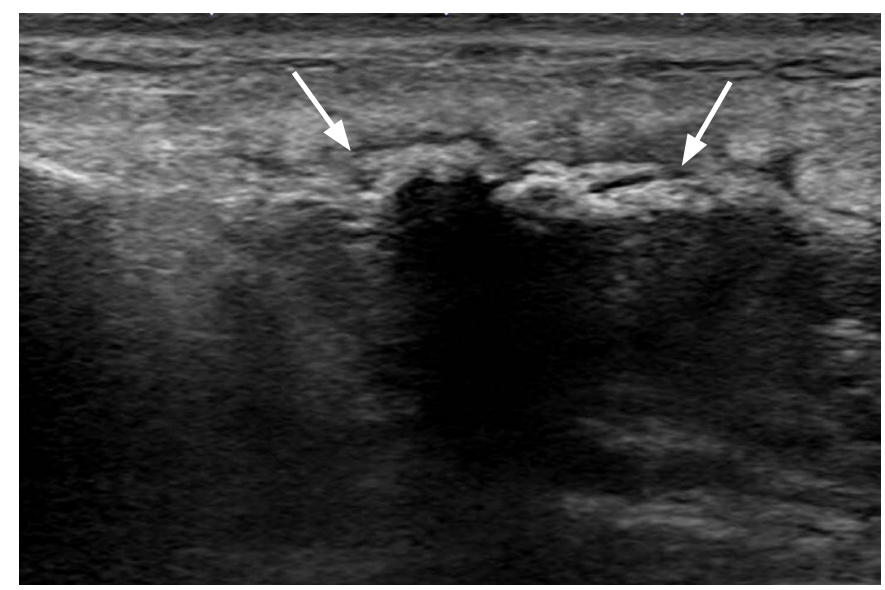

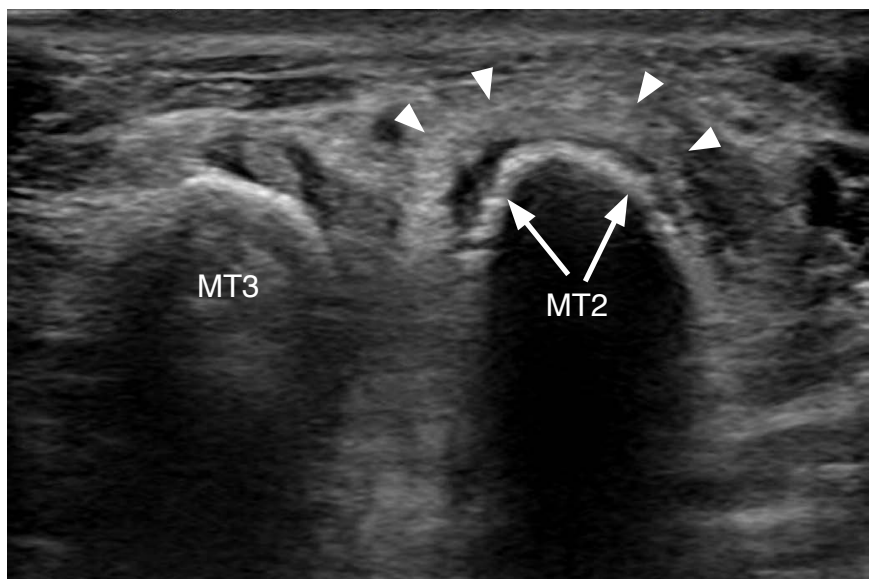

B

Fig. 14. A 50-year-old man with pain in the dorsal foot.

The clinical impression was Morton's neuroma because of second web space tenderness. A. Standing anteroposterior radiograph of the foot shows a minimal periosteal reaction (arrow) at the lateral side of second metatarsal shaft. B. Ultrasonography short-axis view of the painful site, scanning from the dorsal side, shows cortical irregularity (arrows) at the second metatarsal shaft and hyperechogenicity of surrounding soft tissue (arrowheads). C. Ultrasonography long-axis view of the painful site, scanning from the dorsal side, shows cortical thickening and irregularity (arrows) at the dorsolateral cortex of the second metatarsal shaft. MT, metatarsal bone. 
Nonetheless, the examiner should also be familiar with other cortical irregularities that may mimic fractures, such as nutrient vessels, physeal plates, cortical erosions, sesamoid bone, or ossicles. The differential points are the typical location, absence of proper trauma history, no other signs of injury, and no significant pain when adequate pressure is loaded over the site with the transducer [66].

\section{Submetatarsal Bursitis}

Submetatarsal fat-pad abnormalities of the forefoot, including adventitious bursitis (submetatarsal bursitis), are usually caused by repeated friction and pressure on the foot during walking or prolonged weight-bearing [67]. Submetatarsal bursitis is one of the causes of metatarsalgia $[67,68]$ and must be differentiated from the others. On US, submetatarsal bursitis is visible as an ill-/well-defined

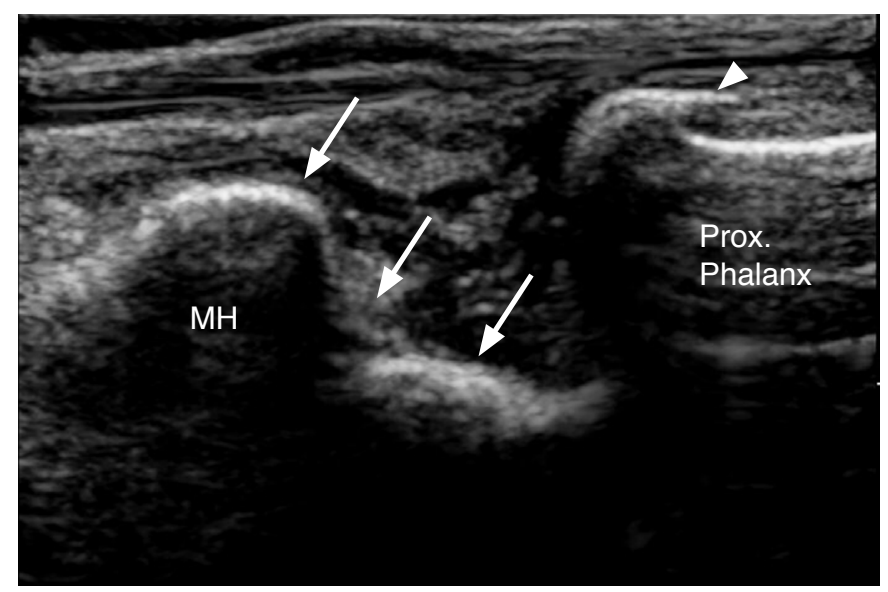

A

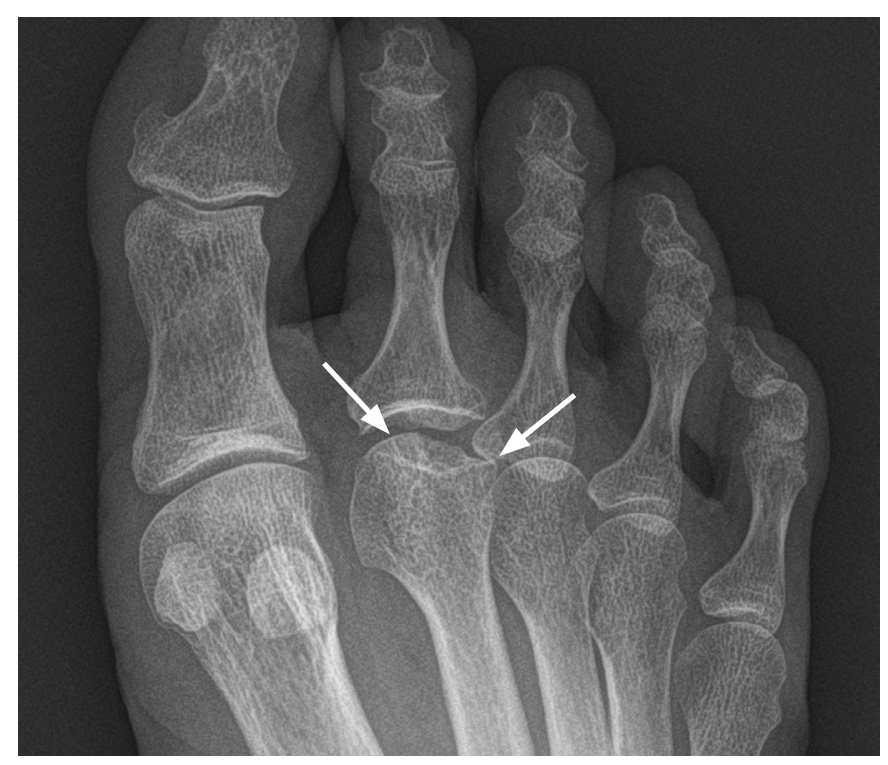

low-echoic lesion in the plantar fat pad, which is often compressible and sometimes contains fluid. Gregg et al. described that ill-defined bursitis is more compressible (Video clip 6), whereas well-defined bursitis is less compressible and even mobile. Hyperemia on power Doppler can be found in submetatarsal bursitis [69].

Abnormalities of the submetatarsal fat pad are also commonly found in asymptomatic patients, yet the distribution and imaging findings are different. An MRI study of submetatarsal fat-pad lesions revealed that asymptomatic lesions were most frequently found beneath the first and fifth MTP joints and showed T1 isointensity and $\mathrm{T} 2$ hypointensity, which suggests that these lesions were predominantly fibrosis. However, symptomatic lesions were often seen under the second or third MTP joint, and they were larger in size and showed mixed to hyperintense $\mathrm{T} 2$ signal intensity, suggesting a fluid component [67]. Similarly, a recent study showed

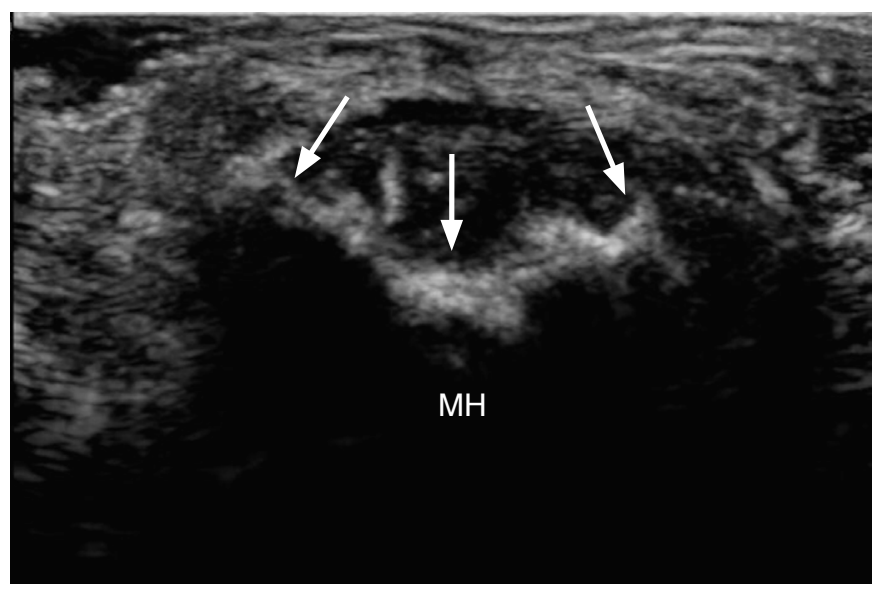

B

Fig. 15. A 59-year-old woman with second toe pain.

A. Ultrasonography long-axis view of the second metatarsophalangeal (MTP) joint scanning from the dorsal side shows a depression of the metatarsal head ( $\mathrm{MH}$; arrows). Note an osteophyte (arrowhead) at the proximal phalangeal base, which is a feature of secondary degenerative changes. B. Ultrasonography short-axis of the second metatarsal bone head scanning from the dorsal side shows flattening of the dorsal MH (arrows). C. Oblique radiograph of the foot shows flattening of the MH (arrows) and secondary degenerative changes of the MTP joint. 
that early RA patients tended to have submetatarsal bursitis more frequently than healthy controls. Furthermore, centrally located (beneath second to fourth MTP joints) bursitis is not uncommon in RA patients, whereas normal controls rarely have an abnormality in these regions [33].

There are limited studies regarding the pathogenesis or imaging findings of submetatarsal fat-pad lesions in patients with metatarsalgia. However, submetatarsal fat-pad lesions are occasionally seen on US imaging and are worth reporting. Therefore, when there is submetatarsal bursitis that is correlated with the location of pain, showing pain provocation by palpation/ compression with the US probe might allow radiologists to suggest a diagnosis.

US is increasingly used to evaluate patients who present with metatarsalgia. Unlike cross-sectional imaging modalities such as MRI, US examinations are usually concluded during scanning, which requires a high degree of intention to scan the proper place where the true pathology is located. Therefore, radiologists should be familiar with the various causes of metatarsalgia, possible differential diagnoses, and their US imaging features.

ORCID: Hye Min Son: https://orcid.org/0000-0003-1748-0701; Jee Won Chai: https:// orcid.org/0000-0003-1630-1863; Yong Hee Kim: https://orcid.org/0000-0003-0033787X; Dong Hyun Kim: https://orcid.org/0000-0002-3871-7002; Hyo Jin Kim: https:// orcid.org/0000-0002-0549-5722; Jiwoon Seo: https://orcid.org/0000-0002-18102342; Sung Moon Lee: https://orcid.org/0000-0002-2675-3209

\section{Author Contributions}

Conceptualization: Son HM, Chai JW. Data acquisition: Son HM, Chai JW, Kim YH, Kim DH, Kim HJ, Seo J, Lee SM. Data analysis or interpretation: Son HM, Chai JW, Kim YH, Kim DH, Kim HJ, Seo J, Lee SM. Drafting of the manuscript: Son HM, Chai JW. Critical revision of the manuscript: Son HM, Chai JW, Kim YH, Kim DH, Kim HJ, Seo J, Lee SM. Approval of the final version of the manuscript: all authors.

\section{Conflict of Interest}

No potential conflict of interest relevant to this article was reported.

\section{Acknowledgment}

This work was supported by the 2020 Yeungnam University Research Grant.

\section{Supplementary Material}

Video clip 1. A 64-year-old woman with Morton's neuroma. The short-axis view of the intermetatarsal space scanning from the plantar side shows a low-echoic mass in the intermetatarsal space at the level of metatarsal head (MT). In the sonographic Mulder test, while the examiner squeezes the patient's forefoot with the unused hand, the mass protrudes superficially to the plantar aspect, showing a gingko-leaf appearance (https://doi.org/10.14366/usg.21193.v001).

Video clip 2. A 20-year-old man with Morton's neuroma and intermetatarsal bursitis. The long-axis view of intermetatarsal space, scanning from the plantar side, shows a Morton's neuroma closely abutting the intermetatarsal bursitis. When the examiner compresses the dorsal side of the intermetatarsal space, Morton's neuroma and intermetatarsal bursitis become distinguishable from each other. Morton's neuroma shows a minimal change in size and shape in response to compression at the dorsal side, whereas intermetatarsal bursitis shows a significant change in size and collapse. DTML, deep transverse metatarsal ligament (https://doi.org/10.14366/usg.21193.v002).

Video clip 3. A 72-year-old woman with a full-thickness plantar plate injury. The long-axis view of the plantar plate, scanning from the plantar side, shows a full-thickness defect at the central distal $\mathrm{PP}$, between the MH and FT. Note the osteophyte formation at the proximal phalangeal base, which is a secondary finding of PP injury. FT, flexor tendon; $\mathrm{MH}$, metatarsal head; PP, plantar plate (https://doi.org/10.14366/usg.21193.v003).

Video clip 4. A 57-year-old woman with a full-thickness PP injury. The long-axis view of the PP, scanning from the plantar side, shows a full-thickness defect at the central distal PP with retraction, and the submetatarsal fat herniates into the metatarsophalangeal (MTP) joint during dorsiflexion of the toe. FT, flexor tendon; $\mathrm{MH}$, metatarsal head; PP, plantar plate (https://doi.org/10.14366/usg.21193.v004).

Video clip 5. A 67-year-old woman with a partial-thickness plantar plate injury. The long-axis view of the PP, scanning from the plantar side, shows localized thinning of the PP at the middle to distal PP. Note the "cartilage interface sign," defined as a hyperechoic surface of the MH cartilage prominent at the site of the PP injury by intervening joint effusion. FT, flexor tendon; $\mathrm{MH}$, metatarsal head; PP, plantar plate (https://doi.org/10.14366/usg.21193.v005).

Video clip 6. A 43-year-old woman with submetatarsal bursitis who had intermittent pain after prolonged walking. The short-axis view of the submetatarsal fat pad, scanning from the plantar side, shows an ill-defined low-echoic lesion in submetatarsal fat-pad adjacent to the FT of second toe. Repeated compression with the ultrasonography transducer causes mild collapse of the lesion during compression. FT, flexor tendon; MH, metatarsal head; PP, plantar plate (https://doi.org/10.14366/usg.21193.v006). 


\section{References}

1. Gates LS, Arden NK, Hannan MT, Roddy E, Gill TK, Hill CL, et al. Prevalence of foot pain across an International Consortium of Population-Based Cohorts. Arthritis Care Res (Hoboken) 2019;71:661-670.

2. Thomas MJ, Roddy E, Zhang W, Menz HB, Hannan MT, Peat GM. The population prevalence of foot and ankle pain in middle and old age: a systematic review. Pain 2011;152:2870-2880.

3. Clinical Practice Guideline Forefoot Disorders Panel; Thomas $J L$, Blitch EL 4th, Chaney DM, Dinucci KA, Eickmeier K, et al. Diagnosis and treatment of forefoot disorders. Section 3. Morton's intermetatarsal neuroma. J Foot Ankle Surg 2009;48:251-256.

4. Clinical Practice Guideline Forefoot Disorders Panel; Thomas $J L$, Blitch EL 4th, Chaney DM, Dinucci KA, Eickmeier K, et al. Diagnosis and treatment of forefoot disorders. Section 2. Central metatarsalgia. J Foot Ankle Surg 2009;48:239-250.

5. Clinical Practice Guideline Forefoot Disorders Panel; Thomas JL, Blitch EL 4th, Chaney DM, Dinucci KA, Eickmeier K, et al. Diagnosis and treatment of forefoot disorders. Section 1: digital deformities. J Foot Ankle Surg 2009;48:230-238.

6. Delzell PB, Tritle BA, Bullen JA, Chiunda S, Forney MC. Clinical utility of high-frequency musculoskeletal ultrasonography in foot and ankle pathology: how ultrasound imaging influences diagnosis and management. J Foot Ankle Surg 2017;56:735-739.

7. Joong MA, El-Khoury GY. Radiologic evaluation of chronic foot pain. Am Fam Physician 2007;76:975-983.

8. Bianchi S. Practical US of the forefoot. J Ultrasound 2014;17:151164.

9. Adams WR 2nd. Morton's neuroma. Clin Podiatr Med Surg 2010;27:535-545.

10. DiPreta JA. Metatarsalgia, lesser toe deformities, and associated disorders of the forefoot. Med Clin North Am 2014;98:233-251.

11. Morscher E, Ulrich J, Dick W. Morton's intermetatarsal neuroma: morphology and histological substrate. Foot Ankle Int 2000;21:558562.

12. Bourke G, Owen J, Machet D. Histological comparison of the third interdigital nerve in patients with Morton's metatarsalgia and control patients. Aust N Z J Surg 1994;64:421-424.

13. Cohen SL, Miller TT, Ellis SJ, Roberts MM, DiCarlo EF. Sonography of Morton neuromas: what are we really looking at? J Ultrasound Med 2016;35:2191-2195.

14. Kasparek M, Schneider W. Surgical treatment of Morton's neuroma: clinical results after open excision. Int Orthop 2013;37:1857-1861.

15. Owens R, Gougoulias N, Guthrie H, Sakellariou A. Morton's neuroma: clinical testing and imaging in 76 feet, compared to a control group. Foot Ankle Surg 2011;17:197-200.

16. Bencardino J, Rosenberg ZS, Beltran J, Liu X, Marty-Delfaut E. Morton's neuroma: is it always symptomatic? AJR Am J Roentgenol
2000;175:649-653.

17. Quinn TJ, Jacobson JA, Craig JG, van Holsbeeck MT. Sonography of Morton's neuromas. AJR Am J Roentgenol 2000;174:1723-1728.

18. Levitsky KA, Alman BA, Jevsevar DS, Morehead J. Digital nerves of the foot: anatomic variations and implications regarding the pathogenesis of interdigital neuroma. Foot Ankle 1993;14:208214.

19. Xu Z, Duan $X, Y u X$, Wang $H$, Dong $X$, Xiang Z. The accuracy of ultrasonography and magnetic resonance imaging for the diagnosis of Morton's neuroma: a systematic review. Clin Radiol 2015;70:351-358.

20. Bignotti B, Signori A, Sormani MP, Molfetta L, Martinoli C, Tagliafico A. Ultrasound versus magnetic resonance imaging for Morton neuroma: systematic review and meta-analysis. Eur Radiol 2015;25:2254-2262.

21. Redd RA, Peters VJ, Emery SF, Branch HM, Rifkin MD. Morton neuroma: sonographic evaluation. Radiology 1989;171:415-417.

22. Read JW, Noakes JB, Kerr D, Crichton KJ, Slater HK, Bonar F. Morton's metatarsalgia: sonographic findings and correlated histopathology. Foot Ankle Int 1999;20:153-161.

23. Shapiro PP, Shapiro SL. Sonographic evaluation of interdigital neuromas. Foot Ankle Int 1995;16:604-606.

24. Torriani M, Kattapuram SV. Technical innovation. Dynamic sonography of the forefoot: the sonographic Mulder sign. AJR Am J Roentgenol 2003;180:1121-1123.

25. Park HJ, Kim SS, Rho MH, Hong HP, Lee SY. Sonographic appearances of Morton's neuroma: differences from other interdigital soft tissue masses. Ultrasound Med Biol 2011;37:12041209.

26. Zanetti M, Strehle JK, Zollinger H, Hodler J. Morton neuroma and fluid in the intermetatarsal bursae on MR images of 70 asymptomatic volunteers. Radiology 1997;203:516-520.

27. Sobiesk GA, Wertheimer SJ, Schulz R, Dalfovo M. Sonographic evaluation of interdigital neuromas. J Foot Ankle Surg 1997;36:364-366.

28. Gimber LH, Melville DM, Bocian DA, Krupinski EA, Guidice MP, Taljanovic MS. Ultrasound evaluation of Morton neuroma before and after laser therapy. AJR Am J Roentgenol 2017;208:380-385.

29. Sharp RJ, Wade CM, Hennessy MS, Saxby TS. The role of MRI and ultrasound imaging in Morton's neuroma and the effect of size of lesion on symptoms. J Bone Joint Surg Br 2003;85:999-1005.

30. Albtoush $\mathrm{OM}$, Xenitidis T, Horger M. Intermetatarsal bursitis as first disease manifestation in different rheumatological disorders and related MR-imaging findings. Rheumatol Int 2019;39:2129-2136.

31. Gregg J, Marks P. Metatarsalgia: an ultrasound perspective. Australas Radiol 2007;51:493-499.

32. Bossley CJ, Cairney PC. The intermetatarsophalangeal bursa: its significance in Morton's metatarsalgia. J Bone Joint Surg $\mathrm{Br}$ 1980;62-B:184-187. 
33. Dakkak YJ, Niemantsverdriet E, van der Helm-van Mil AH, Reijnierse $M$. Increased frequency of intermetatarsal and submetatarsal bursitis in early rheumatoid arthritis: a large case-controlled MRI study. Arthritis Res Ther 2020;22:277.

34. Nery C, Umans H, Baumfeld D. Etiology, clinical assessment, and surgical repair of plantar plate tears. Semin Musculoskelet Radiol 2016;20:205-213.

35. Nery C, Baumfeld D, Umans H, Yamada AF. MR imaging of the plantar plate: normal anatomy, turf toe, and other injuries. Magn Reson Imaging Clin N Am 2017;25:127-144.

36. Nery C, Coughlin MJ, Baumfeld D, Mann TS. Lesser metatarsophalangeal joint instability: prospective evaluation and repair of plantar plate and capsular insufficiency. Foot Ankle Int 2012;33:301-311.

37. Umans RL, Umans BD, Umans $H$, Elsinger E. Predictive MRI correlates of lesser metatarsophalangeal joint plantar plate tear. Skeletal Radiol 2016;45:969-975.

38. Doty JF, Coughlin MJ, Weil L Jr, Nery C. Etiology and management of lesser toe metatarsophalangeal joint instability. Foot Ankle Clin 2014;19:385-405.

39. Klein EE, Weil L Jr, Weil LS Sr, Knight J. Musculoskeletal ultrasound for preoperative imaging of the plantar plate: a prospective analysis. Foot Ankle Spec 2013;6:196-200.

40. Gregg J, Silberstein M, Schneider T, Marks P. Sonographic and MRI evaluation of the plantar plate: a prospective study. Eur Radiol 2006;16:2661-2669.

41. Klein EE, Weil L Jr, Weil LS Sr, Knight J. Magnetic resonance imaging versus musculoskeletal ultrasound for identification and localization of plantar plate tears. Foot Ankle Spec 2012;5:359-365.

42. McCarthy $\mathrm{CL}$, Thompson GV. Ultrasound findings of plantar plate tears of the lesser metatarsophalangeal joints. Skeletal Radiol 2021;50:1513-1525.

43. Linklater JM, Bird SJ. Imaging of lesser metatarsophalangeal joint plantar plate degeneration, tear, and repair. Semin Musculoskelet Radiol 2016;20:192-204.

44. Feuerstein CA, Weil L Jr, Weil LS Sr, Klein EE, Fleischer A, Argerakis NG. Static versus dynamic musculoskeletal ultrasound for detection of plantar plate pathology. Foot Ankle Spec 2014;7:259-265.

45. Hodes A, Umans H. Metatarsalgia. Radiol Clin North Am 2018;56:877-892.

46. Umans $H$, Srinivasan R, Elsinger E, Wilde GE. MRI of lesser metatarsophalangeal joint plantar plate tears and associated adjacent interspace lesions. Skeletal Radiol 2014;43:1361-1368.

47. Taljanovic MS, Melville DM, Gimber LH, Scalcione LR, Miller MD, Kwoh CK, et al. High-resolution US of rheumatologic diseases. Radiographics 2015;35:2026-2048.

48. Zhang YH, Li K, Xiao J, Zhang HD, Zhang XY. Comparison of ultrasound, radiography, and clinical investigations in the diagnosis of early rheumatoid synovitis in patients with nonspecific musculoskeletal symptoms: a multicenter cross-sectional study. Med Sci Monit 2018;24:4372-4378.

49. Lopez-Ben R, Bernreuter WK, Moreland LW, Alarcon GS. Ultrasound detection of bone erosions in rheumatoid arthritis: a comparison to routine radiographs of the hands and feet. Skeletal Radiol 2004;33:80-84.

50. D'Agostino MA, Terslev L, Aegerter P, Backhaus M, Balint P, Bruyn $G A$, et al. Scoring ultrasound synovitis in rheumatoid arthritis: a EULAR-OMERACT ultrasound taskforce-Part 1: definition and development of a standardised, consensus-based scoring system. RMD Open 2017;3:e000428.

51. Wakefield RJ, Balint PV, Szkudlarek M, Filippucci E, Backhaus M, D'Agostino MA, et al. Musculoskeletal ultrasound including definitions for ultrasonographic pathology. J Rheumatol 2005;32:2485-2487.

52. Klauser A, Demharter J, De Marchi A, Sureda D, Barile A, Masciocchi $C$, et al. Contrast enhanced gray-scale sonography in assessment of joint vascularity in rheumatoid arthritis: results from the IACUS study group. Eur Radiol 2005;15:2404-2410.

53. Koski JM. Detection of plantar tenosynovitis of the forefoot by ultrasound in patients with early arthritis. Scand J Rheumatol 1995;24:312-313.

54. Suh JY, Park SY, Koh SH, Lee IJ, Lee K. Unusual, but important, peri- and extra-articular manifestations of rheumatoid arthritis: a pictorial essay. Ultrasonography 2021;40:602-616.

55. Ottaviani S, Bardin T, Richette P. Usefulness of ultrasonography for gout. Joint Bone Spine 2012;79:441-445.

56. Thiele RG, Schlesinger N. Diagnosis of gout by ultrasound. Rheumatology (Oxford) 2007:46:1116-1121.

57. Grassi W, Meenagh G, Pascual E, Filippucci E. "Crystal clear": sonographic assessment of gout and calcium pyrophosphate deposition disease. Semin Arthritis Rheum 2006;36:197-202.

58. Lai KL, Chiu YM. Role of ultrasonography in diagnosing gouty arthritis. J Med Ultrasound 2011;19:7-13.

59. Wright SA, Filippucci E, McVeigh C, Grey A, McCarron M, Grassi $W$, et al. High-resolution ultrasonography of the first metatarsal phalangeal joint in gout: a controlled study. Ann Rheum Dis 2007;66:859-864

60. Girish G, Melville DM, Kaeley GS, Brandon CJ, Goyal JR, Jacobson JA, et al. Imaging appearances in gout. Arthritis 2013;2013:673401.

61. de Avila Fernandes E, Kubota ES, Sandim GB, Mitraud SA, Ferrari AJ, Fernandes AR. Ultrasound features of tophi in chronic tophaceous gout. Skeletal Radiol 2011;40:309-315.

62. Schwabl C, Taljanovic M, Widmann G, Teh J, Klauser AS. Ultrasonography and dual-energy computed tomography: impact for the detection of gouty deposits. Ultrasonography 2021;40:197206.

63. Magarelli N, Amelia R, Melillo N, Nasuto M, Cantatore F, Guglielmi 
G. Imaging of chondrocalcinosis: calcium pyrophosphate dihydrate (CPPD) crystal deposition disease: imaging of common sites of involvement. Clin Exp Rheumatol 2012;30:118-125.

64. Torriani M, Thomas BJ, Bredella MA, Ouellette H. MRI of metatarsal head subchondral fractures in patients with forefoot pain. AJR Am J Roentgenol 2008;190:570-575.

65. Chowchuen P, Resnick D. Stress fractures of the metatarsal heads. Skeletal Radiol 1998;27:22-25.

66. Hoffman DF, Adams $E$, Bianchi S. Ultrasonography of fractures in sports medicine. Br J Sports Med 2015;49:152-160.

67. Studler U, Mengiardi B, Bode B, Schottle PB, Pfirrmann CW, Hodler
J, et al. Fibrosis and adventitious bursae in plantar fat pad of forefoot: MR imaging findings in asymptomatic volunteers and MR imaging-histologic comparison. Radiology 2008;246:863-870.

68. Bowen CJ, Culliford D, Dewbury K, Sampson M, Burridge J, Hooper $\mathrm{L}$, et al. The clinical importance of ultrasound detectable forefoot bursae in rheumatoid arthritis. Rheumatology (Oxford) 2010;49:191-192.

69. Gregg JM, Schneider T, Marks P. MR imaging and ultrasound of metatarsalgia: the lesser metatarsals. Radiol Clin North Am 2008;46:1061-1078. 